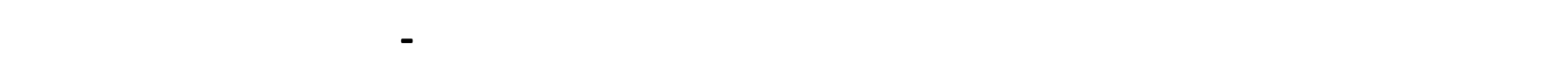
ببهض المغيرل

اليمان عوضسرراج، حنان فتهى زكمى

الكاملت الفناحية البهث: المرأة الرفية - تلوث الغذاء -

ممارسكت الرفيلت.

\section{المقدة والمشكلة البحثية}

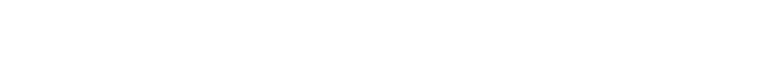

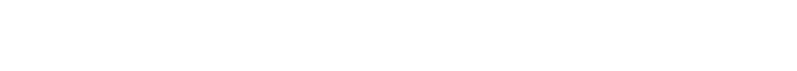
ونجاح حيث يمه بالطاقة اللازمة للففء والحركة والشطيط

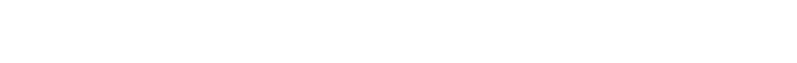

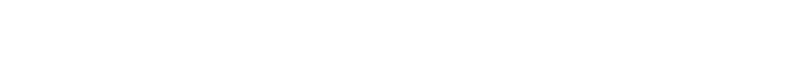

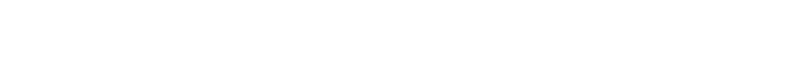

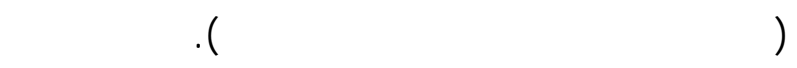
الغذاء يحمل للإنسان الصحة والحيوية والطاقة، إلا أنه ق ق 2

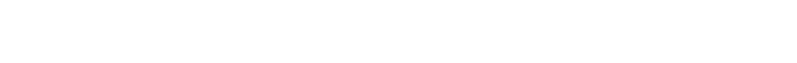

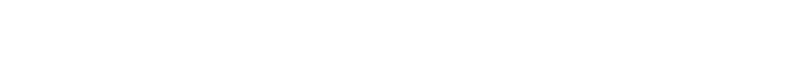

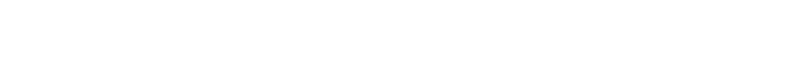
على صحة وحية الإنسان، وخطر التلوث والتسمم الغذائى

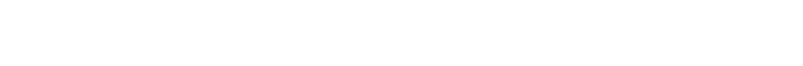

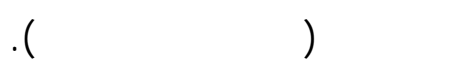

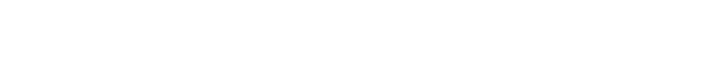

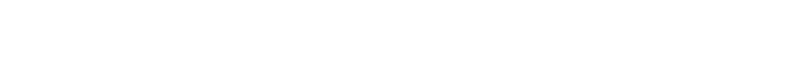

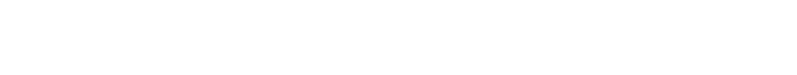

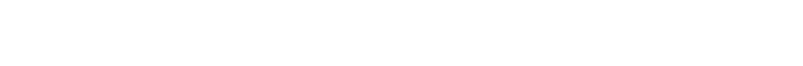

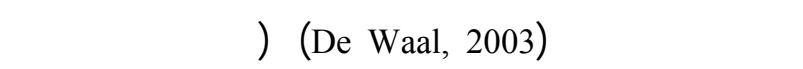

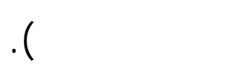

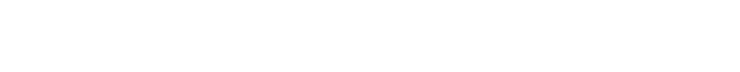

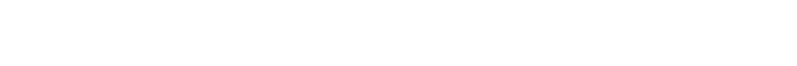

\section{المالضص العرى}

أجرى هذا البهث بهف درلسة مماوسلت الرفيات ف مجل

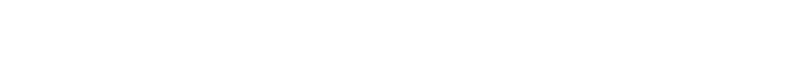
والندالط والهغا بعد اللاهه، والظالكة الشخصسية ألثناء الإعداد

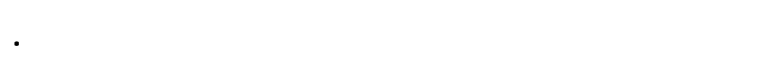

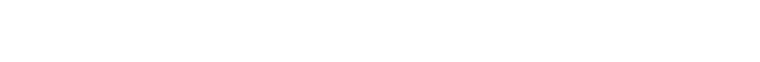
مبحوية فقريق الوقن وزهرة بمحلنلة البحيرة، ومم المستفاء

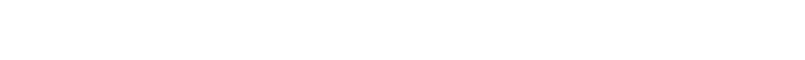

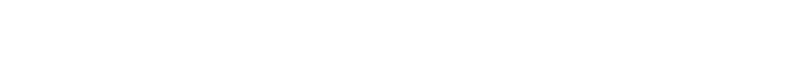

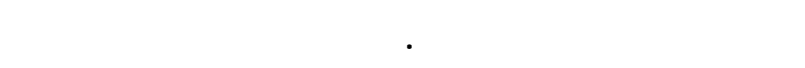

$$
\text { إلى أن: }
$$

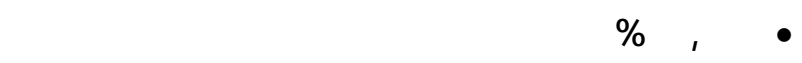
المنخضن فيما ينتطاق بممارسلت تدالط الغذاء عند اللشراء.

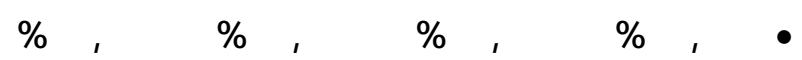
\%or,vr المتوسط فيما ينماق بممارسلتهن أثناء الإعداد والملهى،

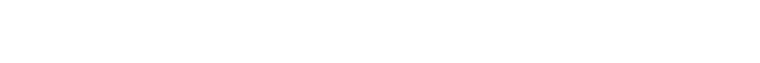

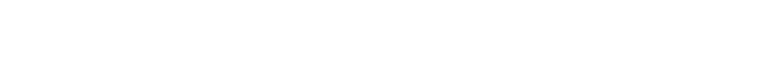
الغذاءمن النائو عل النوالل.

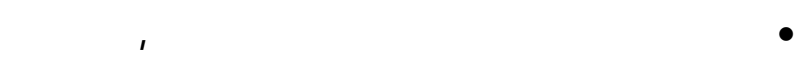

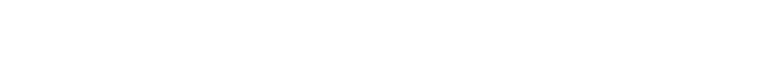

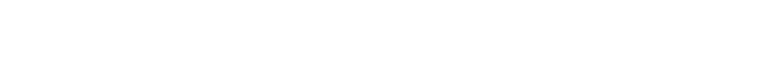
الغذاءمن التالوث كمثغير تلعيع.

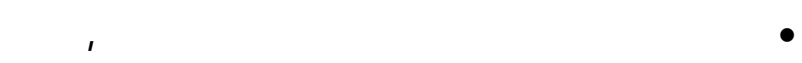

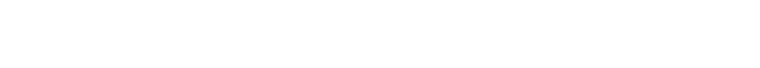

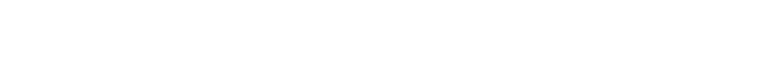
الغذاءمن التلوثكمنغير تلعي. 
نصف الأوراد فى الققيقة تقصهم المعرف بة بال سلوكيت

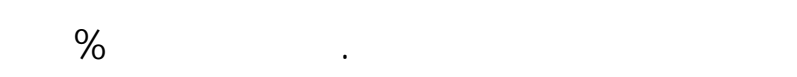

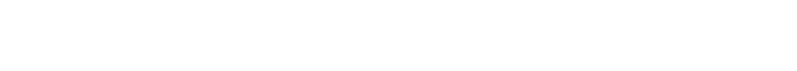

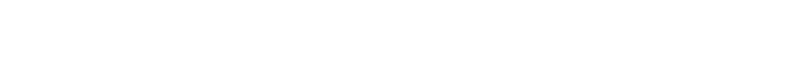

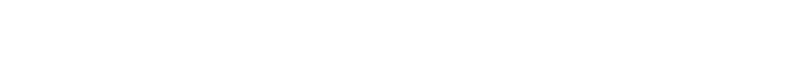

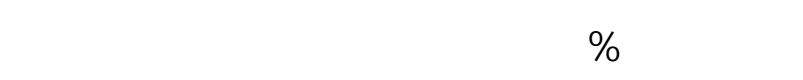
تداطل الطعلم

(Altekruse et al., 1996; Yang et al, 2000; Getting and Kiernan, 2003; Redmond and Griffith, 2003; Mitakakis et al., 2004; Patial et al., 2005; Mullan and Wong, 2009).

وأضضفت هيئة الغذاء والدواء الأمريكية(FDA, 1999) أن البيئة المحطة بأملكن ققيم الغذاء قد تكون مصدرا للتلوث

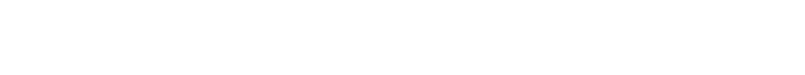

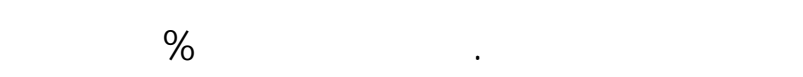

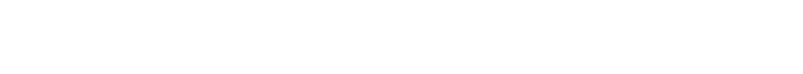

.(Byrd-Bredbener et al., 2007)

كما يؤدى إعداد الأغنية طبريقة خطائة إلى لى

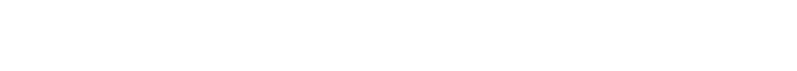

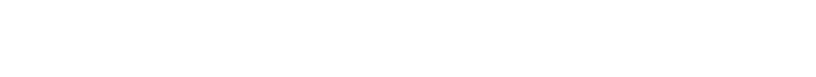

(Exprss Newspaper, 2003)

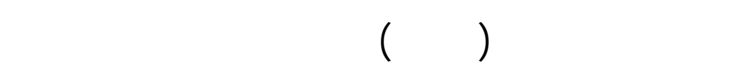

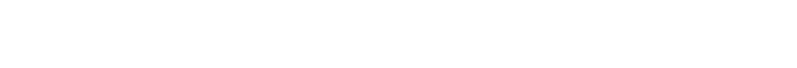
اللسليمة فى لمل ما يتعاق بتحضيروتداول وتخزين الغذاء حتى يكون عدد الميكروبك الملوثة للغذاء فى أضضيق الحدود ومنها مراعة غنل الخضر الخيكروبات الفلكهة جيدا بماء

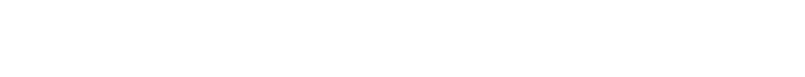

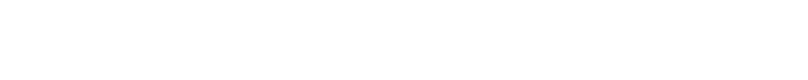
الأولف المستخمة.

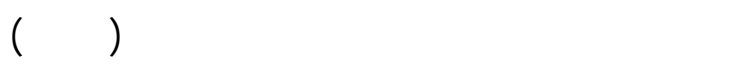

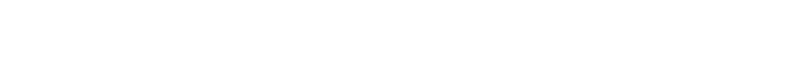

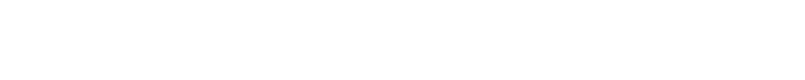

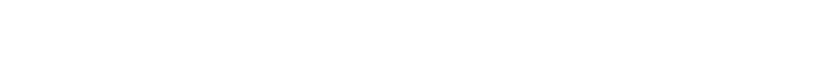

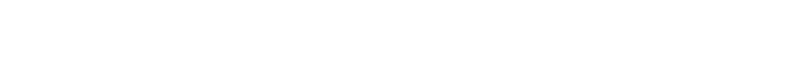

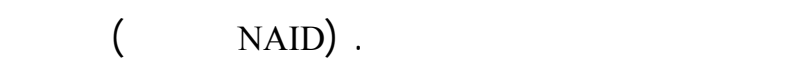

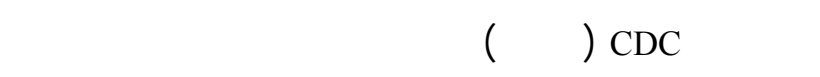

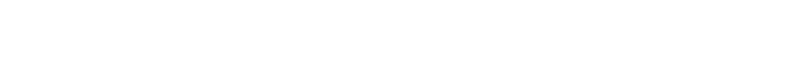

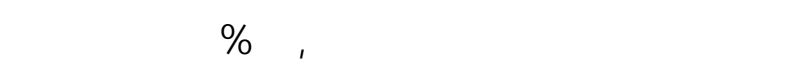

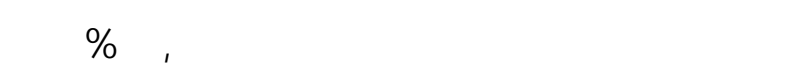

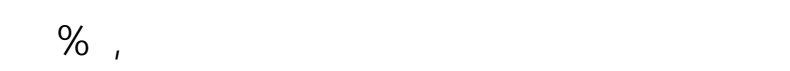
إجمالى عدد الحالات.

وتؤَثر الأمراض الناتجة عن تلوث الغذاء على على الـ عنل

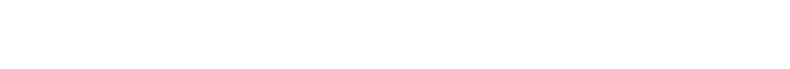

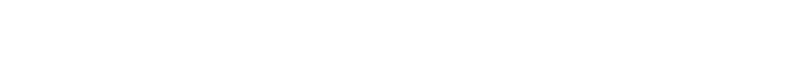
التتجية الفرد المصلب، إذ قدرت الغنائر المادية الناجم مة كن تالك الأمراض فى الولايت المتحدة الأمريكية مابين 0

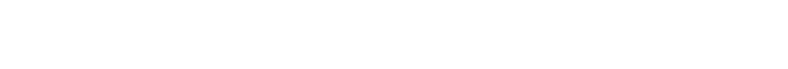

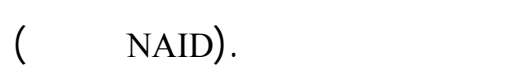

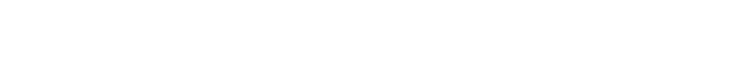

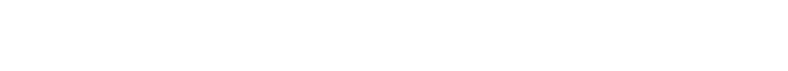

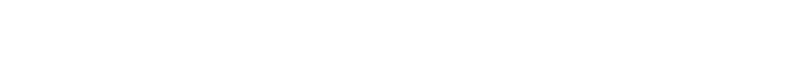

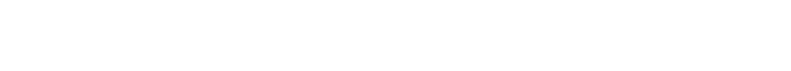
.(WHO,2002)

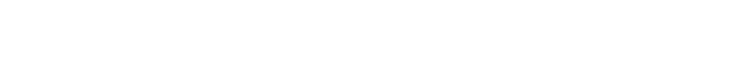

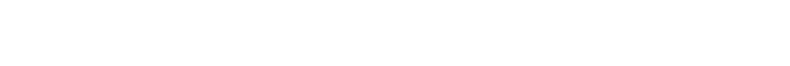

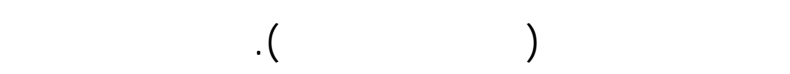

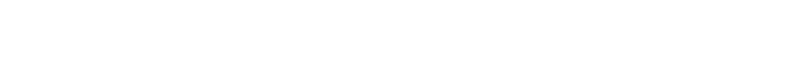

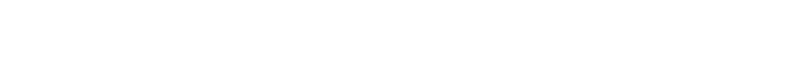

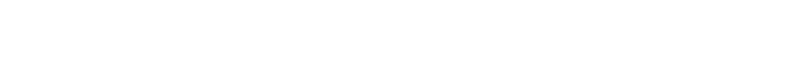

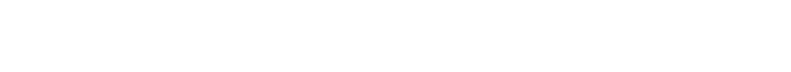

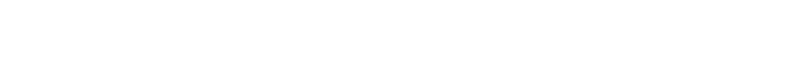

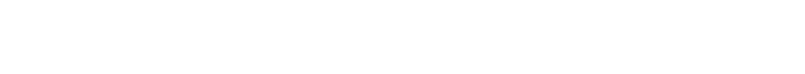




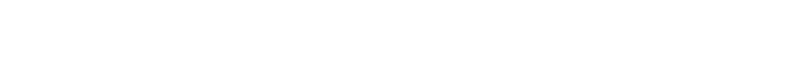

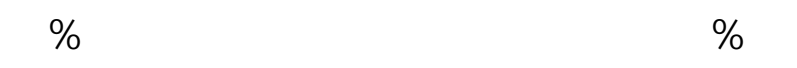

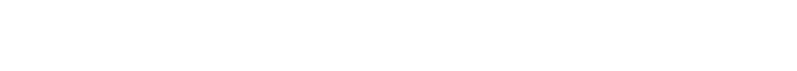
حدوث النالوث العرض للغذاء نتيجة هذه الممارسك الإن الخطائة.

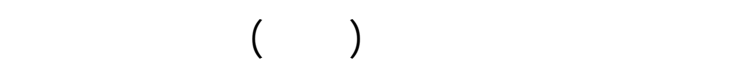

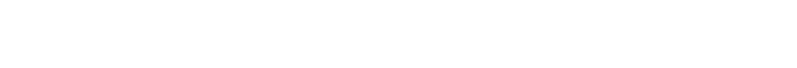

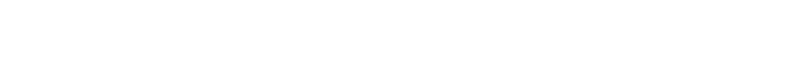

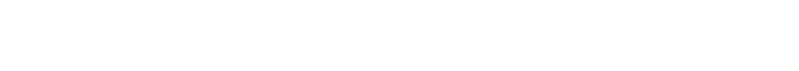

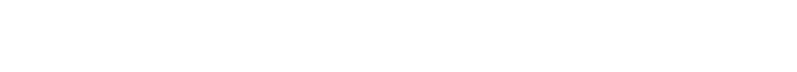

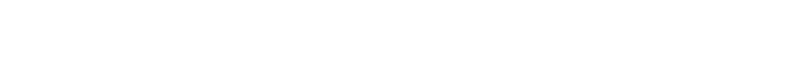

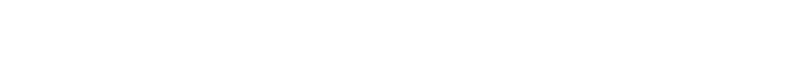

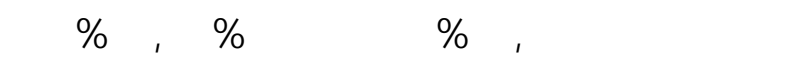
مستوى متوطط وضعيف على التوالى.

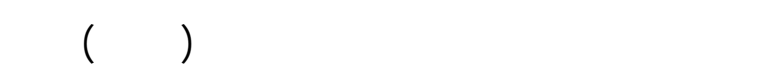

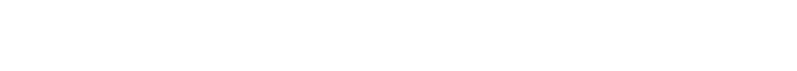

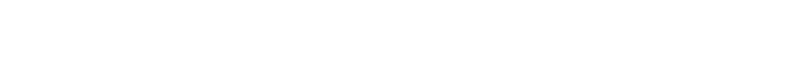

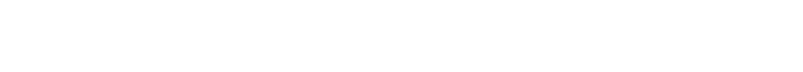

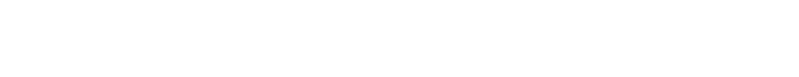

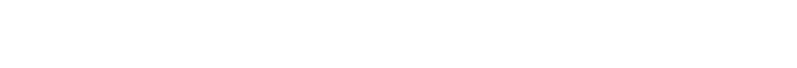
طبرة آمنة

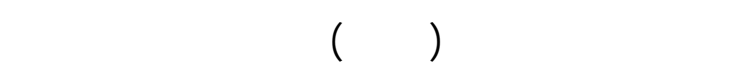

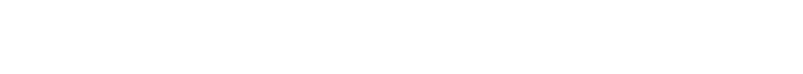
هنه الممارست تؤثثر فى نمو وتكاثر الجراثيم فى الأغنية

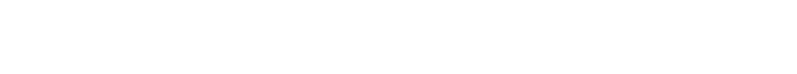
مايطلق عليه التلوث العرضغ.

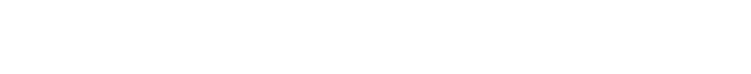

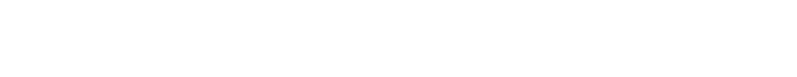

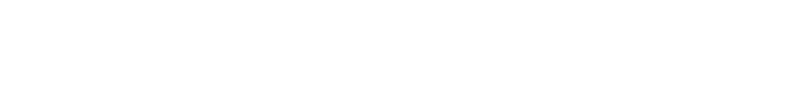

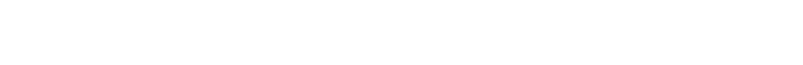

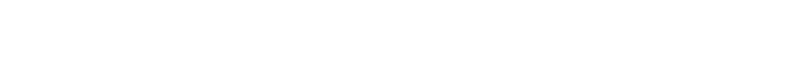

الطعلم وتحضيره من العولمل القى تساعد فى نقليل فرص التلاوث الغذائى.

ويعد المززل مصدرا هلما لانقل الأمراض عن طريق نتلوث الغذاء فقد نكر) (Trepka et al., 2008 أن إعداد الغذاء

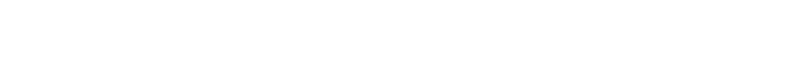

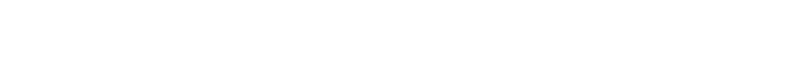
تنتشرسريعا بين الأفراد. كما أشارت نقارير العديد من الدرلسلت فى هذا الصدد الصدرد

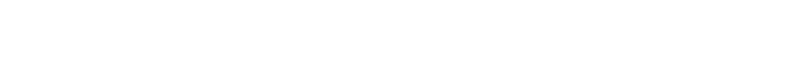

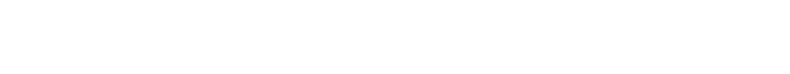
القلة وعى ربك الأسر وممارساتهن غير للسليمة فى تداول الأغنية(Borneff et al.,1998).

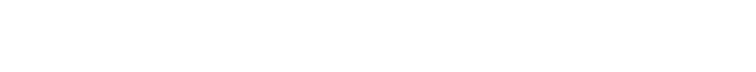
والتعلمل الآمن وللسليم مع الغذاء يعد من الأمور بالغة

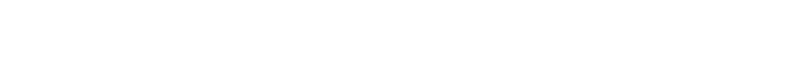
. (WHO; FAO ,2003)

وتعالف جمهورية مصر العربية و بصفة خاصة الريف المصرى من العديد من المشكلات التى تتعلق بتلوث الغذاء

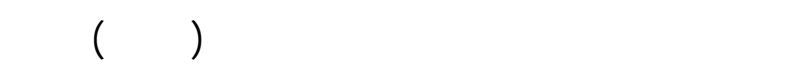
لجريت بمحلظق الإسكندرية والبحيرة ان المرأة الريفية

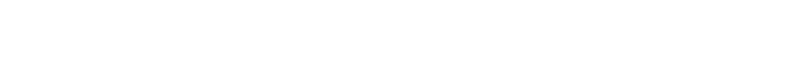
لختيار وإعداد وطهى الطعلم وحمايته من التلوث. كما لُٔلهرت درلسة سهيرتوفيق وليلي الشناوى(1991)

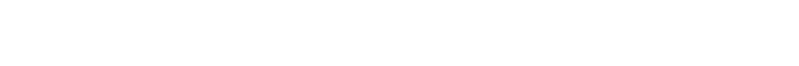
تلوث الغذاء أثناء الإعداد والطهي.

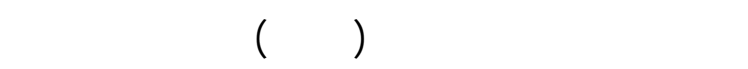
ربة المنزل الريفية فى الحد من التلوث الميكروبى للغذاء

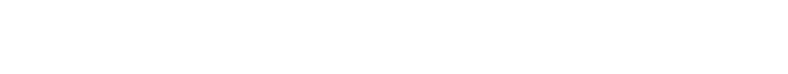

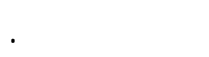

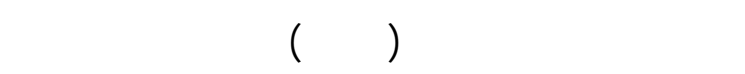
صحة وسلمة الغذاء أن I 1 \% من الناء اللاق لجريت 
- درلسة العلاقلت الارتبطية بين بعض الخصائص المميزة

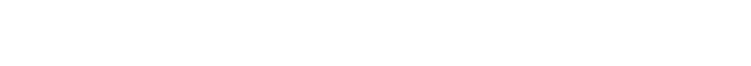

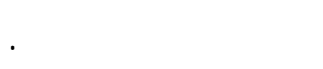

فروض البهث الفرض البحث البه

لتحقق الهدف الثالث للبحث فقد م صياغة الفرض

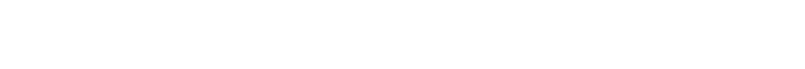
ممارست الريفيت فى مجل الهفظا على الغذاء من التلوث

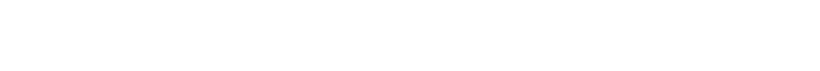
المبحوثة وعدد أفراد الأسرة وعل المبن المبحوثة ومستوى تعليم المبحوثة ومستوى تعليم الزوج ونوع الأسرة، وتعدد مصادر

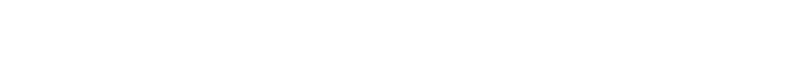

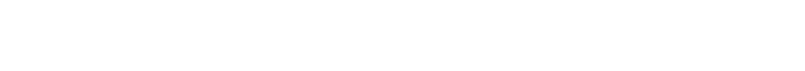
كمتغيرات مسقلة. الفرض الإحصأُ

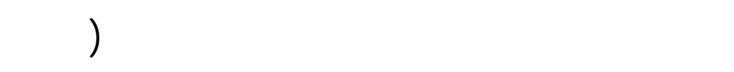
العدم) الذى ينص على علم وجود علاقة ارتبطية مغزوية بين مستوى مماسلت الريفيت فى مجل الحفلظ على الغذاء من التلوث كمتغيرتانع وبين كل من خصائصهن

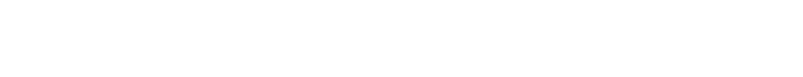
المبحوثة ومستوى تعليم المبحوثة ومستوى تعليم الزوج

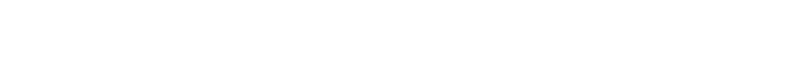
الشهرى ودرجة الافتاح الحضرى ودرجة المشاركة الاجتماعية غير السمية كمتغيرات مسنقة.

النعارف الإجرائية

تلوث الغذاء

يقصد به فى هذه الدرلسة كل مايجعل الغذاء غير صالح

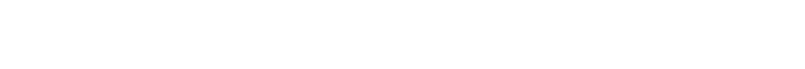

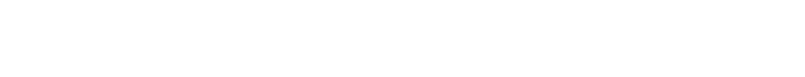

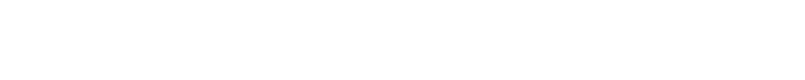

الإنتلجية، لذا فلن مماساتها الخطئة فيما يتعلق بلئس اليب لختيار وإعداد وطه الغذاء وتداوله بعد الخظط، وللثروط

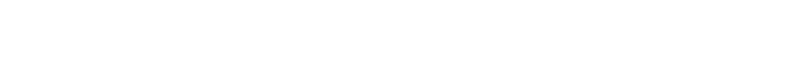

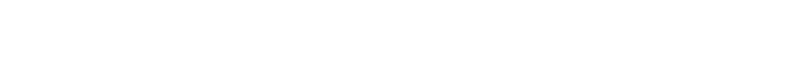
وصحة أفراد لأسرتها، وحتق تتمكن المرأة من القيلم بدورها

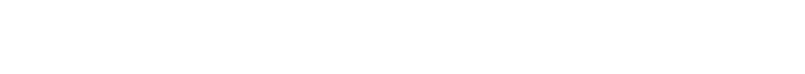

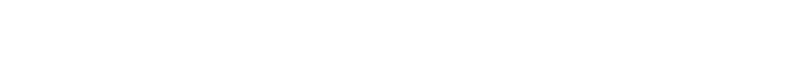
الصحيحة من خلل البرلمج التدريبية والتوعوية التى تسهو

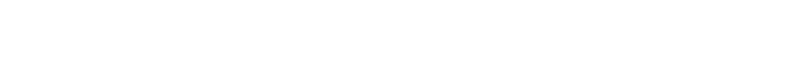

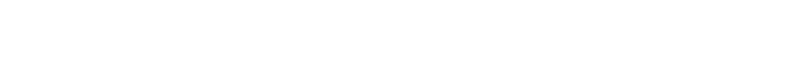

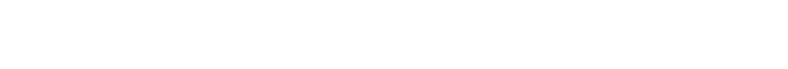
على الاستقرار الف سل والاجتم اعلى وتحقي ق التنمي ـة والرفاهية للمجتمع. الأهمية الثلبقية:

ظرا لأن المرة الريفية هـ المسئولة بشكل مبالثرر عن

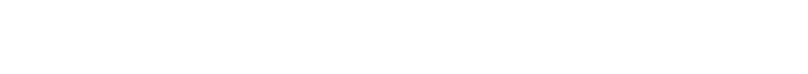

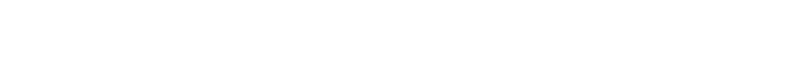

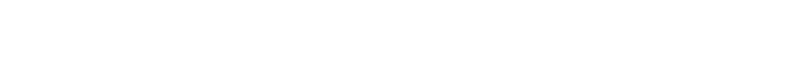

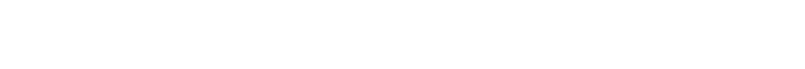
من الضرورة الاهتملم بإعداد وتخطيط البرلمج الإبشاية

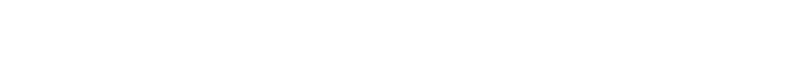
الوعى والقفافة الغذائية المتعلقة بجولة وسلامة الغذاء بينهن بالإضافة إلى توعيتهن بأبعاد قضية تلوث الغذاء وتعديل

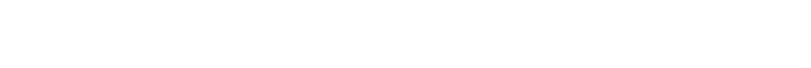
والهظ مما يؤدى إلى للسطرة على كثير من من الأمراض

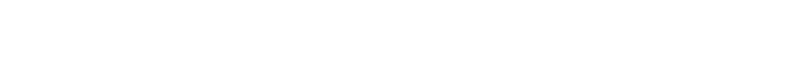
والمجتمع بلكمله. لأهذه البحثية - التعرف على بعض الخصائص المميزة للمبحوثلت.

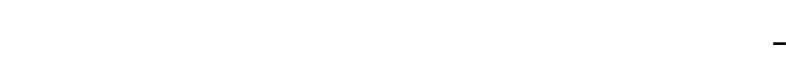
مجل الحفظظ على الغذاء من التلوث. 
المعالجة الكمية للبيلنت أولا:فيما يتهاق بالمتغيرات المسقلة:

- م لمتخدلم الدرجلت الخلم القيلس كل منسن المبحوثة ،عدد افراد الأسرة، الدخل الأسرى. الخدان.

- الحالة التعليمية للمبحوثة والزوج: م تصنيفها إلى: لمه، يقرا ويكتب، البتدائى، إعدادى، ثانوى، جلمعى. لمان. - عهل المبحوثة : م تصنيفه إلى تعله ، ولاتعل وق إعلاء الدرجلت r، أ على التواله. - نوع الأسرة: مُ تصنيفه إلى لسٔسرة بسيطة، ومركبة وتم م إعلاء الدرجك r r، اعلى الترتيب. - تعدد مصادر المعلوملت: مَ قيلسه بإعطاء درجة ولح ـة لل مصدر تتعرض إليه المبحوثة وبرساب لجم اله

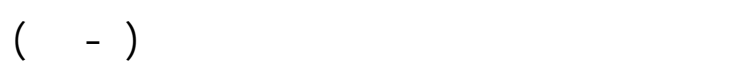

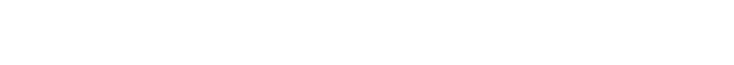
لمصادر المعلوملت إلى ثلاث فئت: ع ع دد م مص مادر

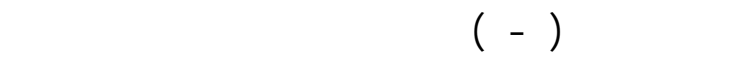

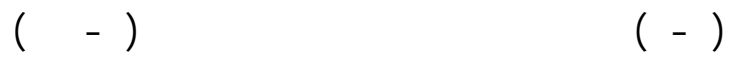
درجة.

- درجة الافتاح الحضرى : قم قيلسه بـ سؤال المبحوثة

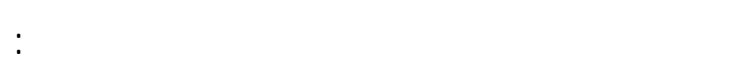

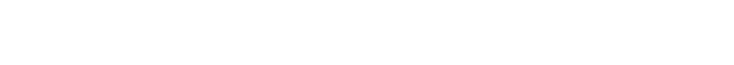

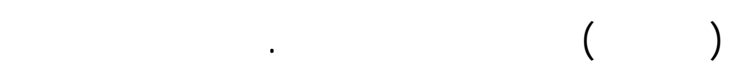

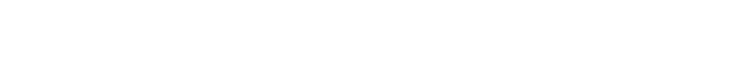

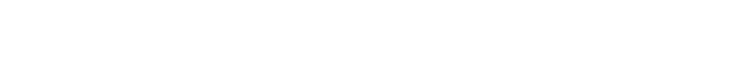

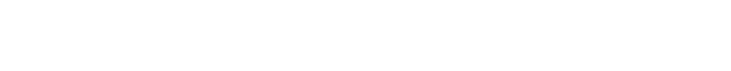
17 درجة، وقم تقيم المبحوثلت وفةا لدرجة الافتاح

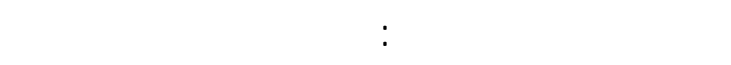
(ألز من 7 درجلت)، الفتاح حضرى متوسط (من 7 -

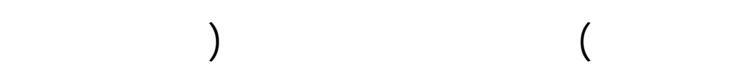

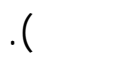

اللثخصية أوظافة الأدوات والأولف والبيئة المحطة الثناء التداطل والاعداد والطه والهنظ

الهفلا عل الهذاءمن التلوث: قصد به فى هذه الدرلسة مدى إتباع المبحوثلت

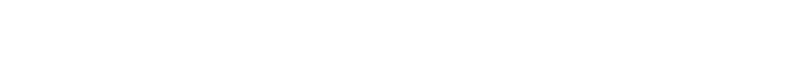

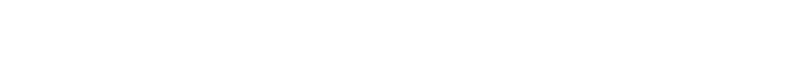
للحصول على غذاء آمن خاله من الملوثلت بما لايؤدى إلى والى الإضرار بصحة المستهلك أوإلحلق الأذى به.

لألرقة الجحثية

لجرى البهث على عينة عثوائية منظمة من زوج ـات الزراع الحائزين بقريق زهرة والوقين بمركز كفر ال دوار

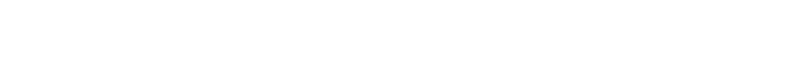
التواله وفقا لسجل خدملت r زراعة بالجمعيتين الزراعيتين

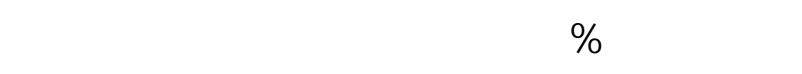
.

وقم جمع البيانت بالمقابلة للثخصية م ن المبحوث لت

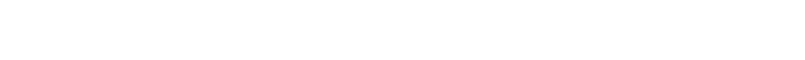
لستمارة الاستبيلن فى صورتها النهائية ج ـزئين رئي سسين:

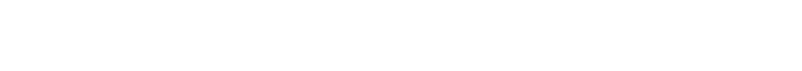

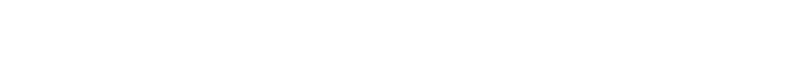

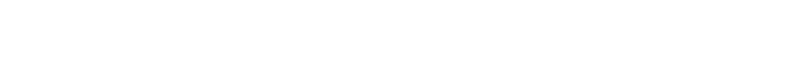

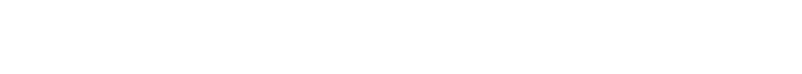
ودرجة الافتاح الحضرى، ودرجة الم شاركة الاجتماعي ـة غيرالسمية الجزء الثانف: يتضمن أسئلة يقم من خلالها تحديد م ستوى

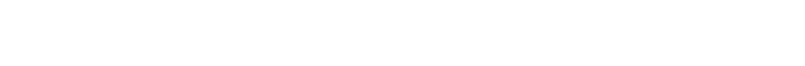
التلوث من خلال خمسة محاور تتضمن: مماسست التهبلت التداول

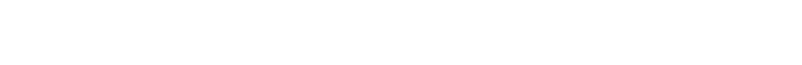

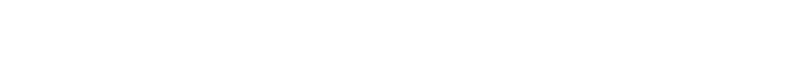
والمماسلت المتعلقة بظافة بيئة الطنخ. 
بالهفظ على الغذاء من التلوث وقد تراوح المدى الفعلى بين

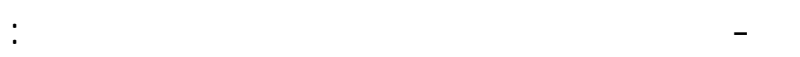

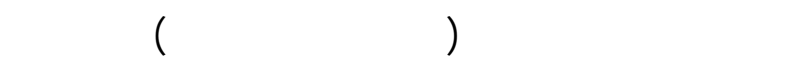

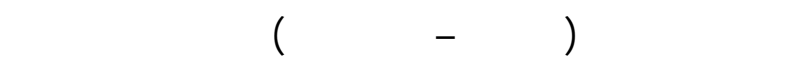
مرتقع (لكثر من 7 · ادرجة).

\section{النتائج ومنالثشتها}

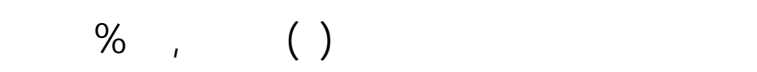

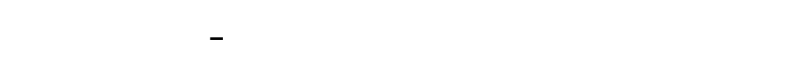

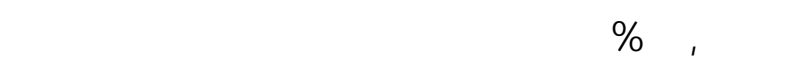

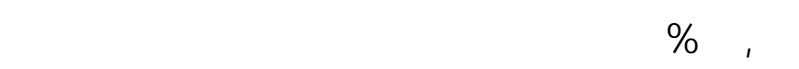
و و

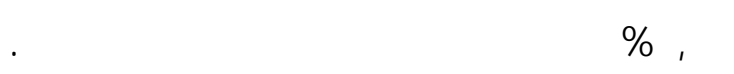

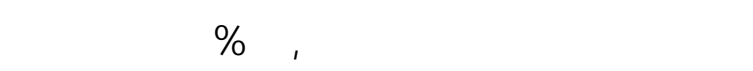

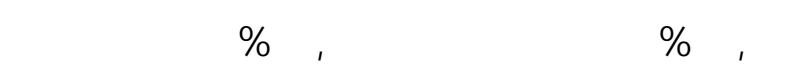

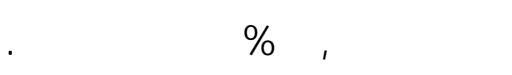

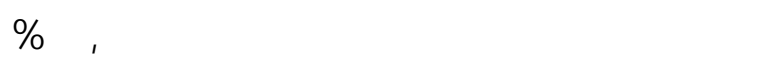

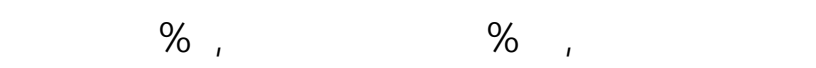

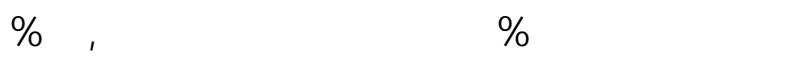

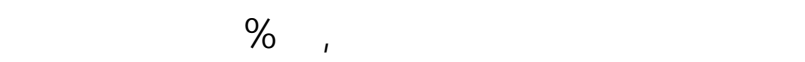
مؤهلات جلمعية.

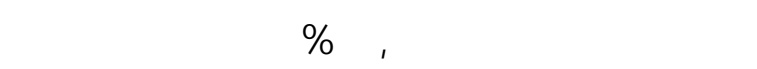

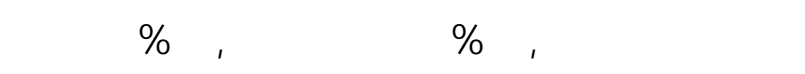

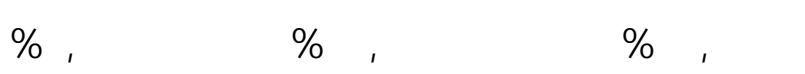
فتط حاصلون على الإبتدائية.
- المشاركة الاجتماعية غير السمية: وم قيلس هـ بـ سؤل

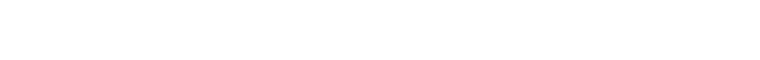
القرية ومشاركتهن فى عل بعض الأغنية فى المولس م والأعياد، والمشاركة فـ المنلسبت للسعيدة، والمشاركة فى العزاء، وعمل جمعي لت الق _ود، وتب الل الأدوات المززلية، والمشاركة فى هل الخلافلت بينسيدات القرية

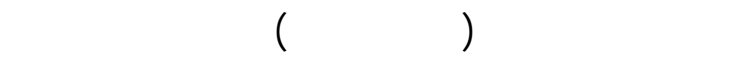
(دائما، لٔحيانا، نادرا، لا) على الترتيب. وبذك تراتك

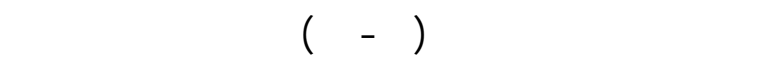
المبحوثلت وفة لدرجة مشاركتهن الاجتماعية إلى ثلاث

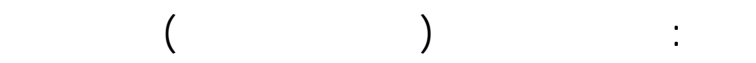

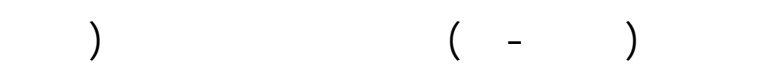

من آمرجة).

\section{ثليافيما يخص بالمتغير التليع:}

(الحفلظ على الغذاء من التلوث) المبحوثة من مماسست تتعلق بخمسة محاور: -مماسات التداول عند الثدراء (0 عبارت) - ممارسات الإعداد والطه (rا عبارة) - مماسست التداول والحظظ بعد الطه (9 عبارات). - مماسلت الظلفة الشخصية (7 عبارات). - ممارسلت متعلقة بظفة بيئة الطبخ (ع ا عبارة). وقم قيلس مستوى مماyسة المبحوثة لبنود كل محور عن طريق جملة ما تحصل عليه المبحوثة من درجلت تعبر عن

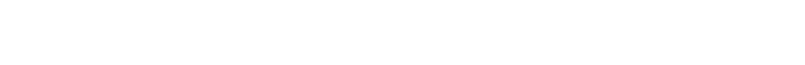
المبحوثة بـ درجلت فى حالة المماسة الصحيحة، ودرجتلن

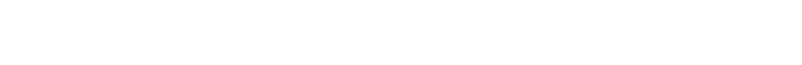
غير الصحيحة.

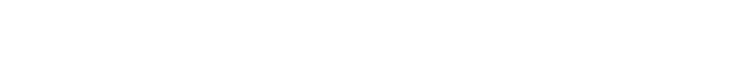

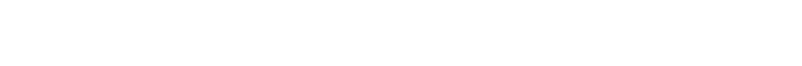

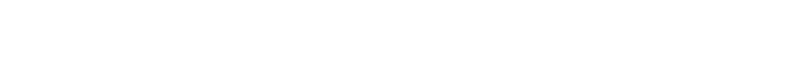




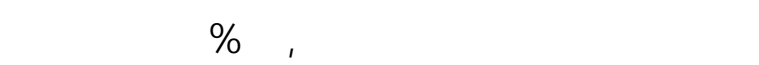

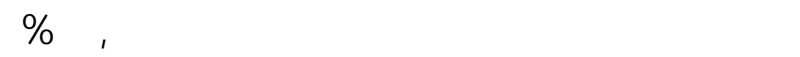

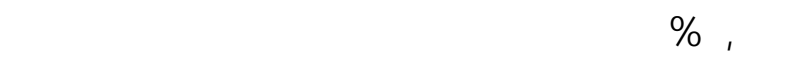

$$
\text { والمرفع. }
$$

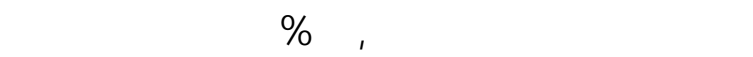

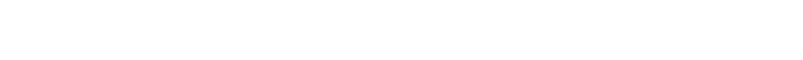

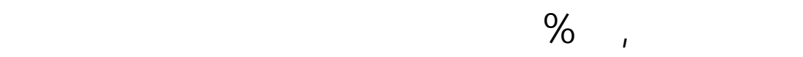
الاجتماعية غير الرسمية المنخفضة.

وفيما يختص بمصادر المعلوملت فإن الغالبية الظمه ق

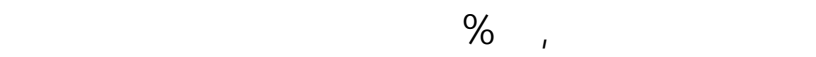

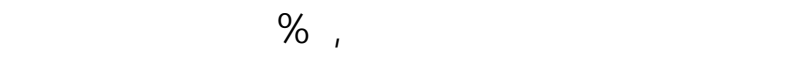

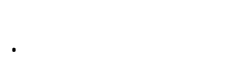

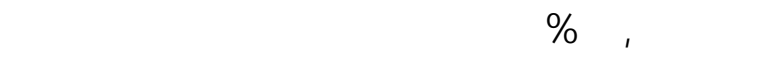

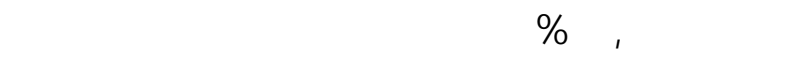
والمرقفع.

تشير النتائج بجدول(r) لن 0\% فتط من المبحوثلت

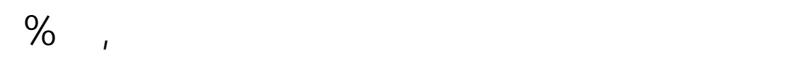

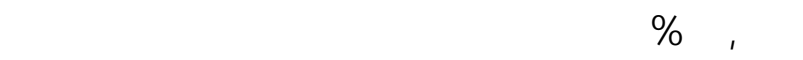

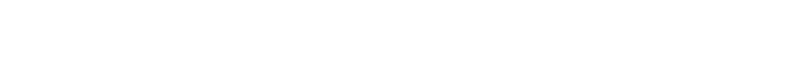

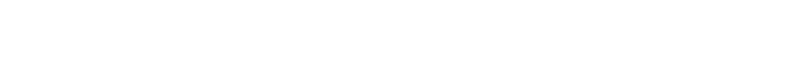

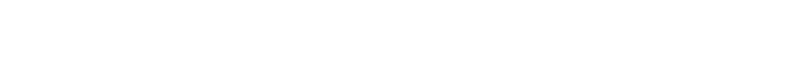

جطل r. توزنع المبحوثلت وفا لفيم الرقمية الدالة عل

\begin{tabular}{|c|c|c|}
\hline$\%$ & عدد & الفئلت - (الف \\
\hline $0,, r q$ & $\Lambda \mu$ & منغفضض (ألَ من 9 درجات ) \\
\hline$r 0, \mathrm{r}$ & 0 . & متوبط (من 9 - -" أ درجة) \\
\hline $0, \cdots$ & $\mathrm{V}$ & مرققع (ألكثرمن سا درجة ) \\
\hline $1 \cdot \cdot$ & $1 \varepsilon$. & إجمالd \\
\hline
\end{tabular}

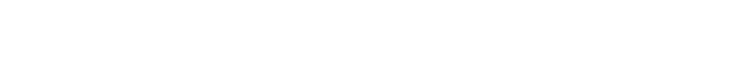

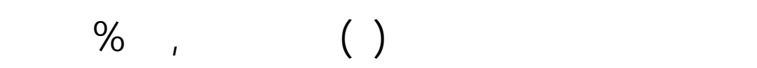
المبحوثتا قيمن لحيانا بلاشراء من الباعة الجائلين وأن

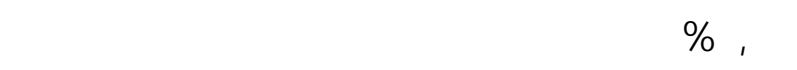
ذلك لعدم وجوسسوق بالقرية.

\begin{tabular}{|c|c|c|}
\hline$\%$ & عנد & الخصأص \\
\hline$r \wedge, 0 v$ & $\varepsilon$. & مبلسنة : فئل \\
\hline$\mu q, r \wedge$ & 00 & Or- "rTua \\
\hline${ }^{\mu} r, 10$ & $\varepsilon 0$ & "بمسنة فلكثر \\
\hline $1 \ldots$ & $1 \varepsilon$. & \\
\hline $7 \cdot, \mathrm{VI}$ & 10 & أقالق من 7 أفر ادر \\
\hline ro,vr & 0. & \\
\hline $\mathrm{r}, \mathrm{OV}$ & 0 & لكثر من 9 أفراد \\
\hline $1 .$. & IE. & المجموع \\
\hline$v^{\mu} 7$ & $1 . \mu$ & نوطة المسرة: \\
\hline$r 7, \varepsilon$ & rV & بسطية \\
\hline $1 \ldots$ & $1 \varepsilon$. & المجموع \\
\hline 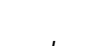 & 110 & \\
\hline IV, 9. & ro & لالتعط \\
\hline $1 \cdots$ & $1 \varepsilon$. & المجموع \\
\hline
\end{tabular}

جدط I ـ توزع المبحوثلت وقا لخصائصهن المميزة

\begin{tabular}{|c|c|c|}
\hline & & ميستوى تعليم المبحوثة \\
\hline 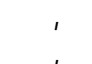 & हा & قرَاة وتكت \\
\hline $0, v$ & $\Lambda$ & \\
\hline $1 \cdot, \cdot \cdot$ & $1 \varepsilon$ & إعدادى \\
\hline$r\rceil, \varepsilon$. & rV & ثأنوى \\
\hline $10, \mathrm{v}$ & $r r$ & \\
\hline 1. & IE. & ألمجموع 1 \\
\hline & & إِ مستوى تعليم الزوج: \\
\hline IV, & ro & قرأويكتب \\
\hline$\mu$, & 0 & \\
\hline $1 \cdot, 1$ & 10 & إعدادى \\
\hline ro,v. & 0. & تشأنوى \\
\hline $10, v$ & r & جلمعى \\
\hline
\end{tabular}

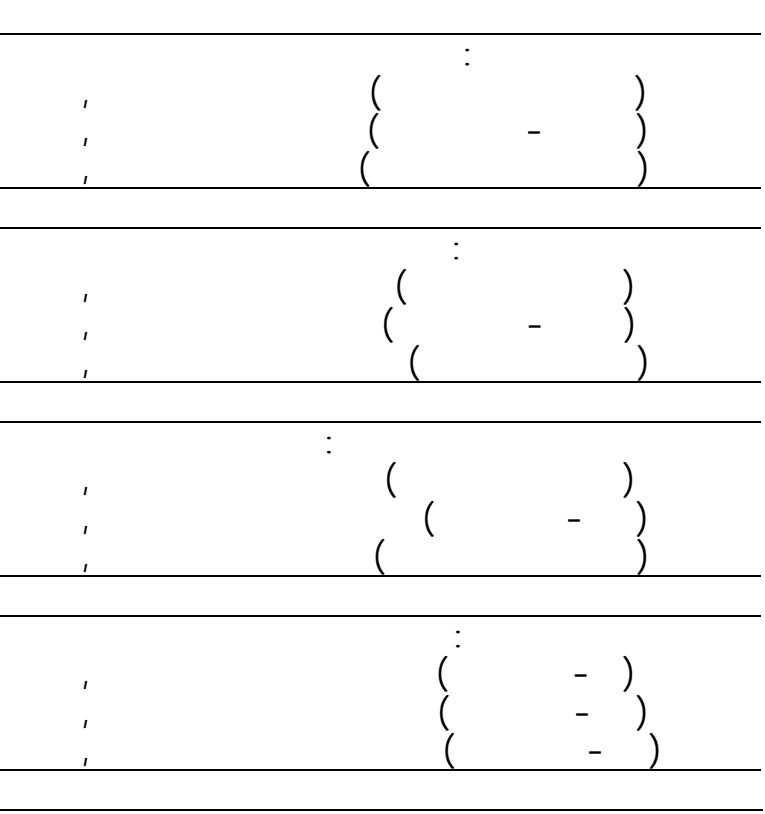




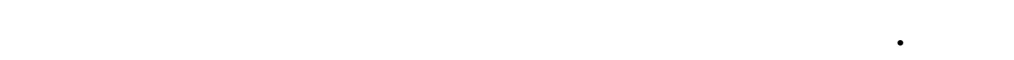

\begin{tabular}{|c|c|c|c|c|c|c|c|c|}
\hline \multicolumn{2}{|c|}{ لإجمال } & \multicolumn{2}{|c|}{ لبدا } & \multicolumn{2}{|c|}{ لحيلنا } & \multicolumn{2}{|c|}{ داكما } & \multirow[t]{2}{*}{ الممارسة } \\
\hline$\%$ & عدد & $\%$ & عدد & $\%$ & عدد & $\%$ & عدد & \\
\hline $1 \ldots$ & $1 \varepsilon$. & $\mu \cdot, \mathrm{Vl}$ & $\varepsilon \mu, \cdots$ & $7 \cdot, \mathrm{V} r$ & 10 & $\Lambda, 0 \mathrm{~V}$ & Ir & I.شراء الطعلمaن الباعة الجائلين لرخص ثمنه \\
\hline $1 \cdots$ & $1 \varepsilon$. & $71, \varepsilon \mu$ & $\Lambda\urcorner, \cdots$ & ro, $\cdot$ & ro & Ir,OV & 19 & r. التلكذدة من تاريخ صلفة الأغذية المعبأة \\
\hline $1 \cdots$ & $1 \varepsilon$. & rq,५ & $\varepsilon 1, \cdot \cdot$ & $00, \cdots$ & VV & $10, \mathrm{~V} \mid$ & $r r$ & ". لمتبعاد العبوات المنبعجة اوالمنقخة عند اللثراء \\
\hline $1 \cdots$ & $1 \varepsilon$. & $1 \cdot, \cdots$ & $1 \cdot \varepsilon, \cdot \cdot$ & $79,{ }^{9} 9$ & $9 \mathrm{~V}$ & $r \cdot, V I$ & rq & ع. لستبعاد العبوات المعرضة للثهس عند للشراء \\
\hline $1 \cdots$ & $1 \varepsilon$. & $7 \cdot, \cdot \cdot$ & $\Lambda \varepsilon, \cdots$ & rr,rq & $\varepsilon \Lambda$ & $0, \mathrm{Vl}$. & $\Lambda$ & 0. تجنبشراءالأغنية المضف لهامواد حلظة \\
\hline
\end{tabular}

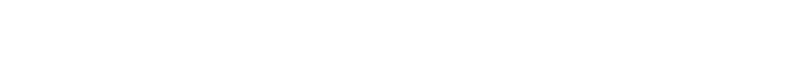

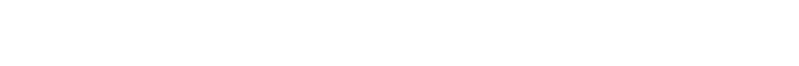
الأغنية وينعكس بدوره على صحة الأسرة الريفية.

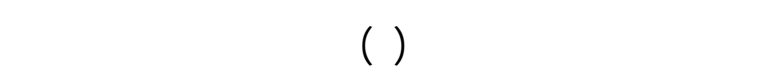

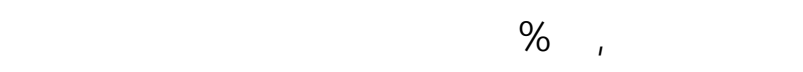

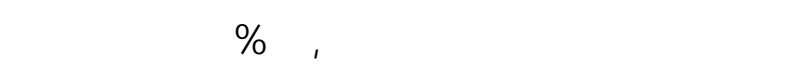
يكتفن بغسل الفوله والخضروات دون قعها فى ماء وخل

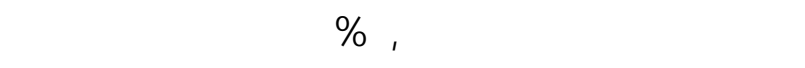

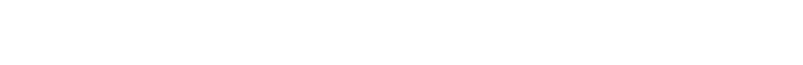

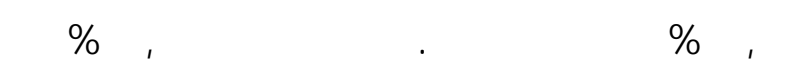
المبحوثلت يقمن دائما بترك البيض على النار لمدة لانظ عن 0 دقائق بعد غليان الماء.

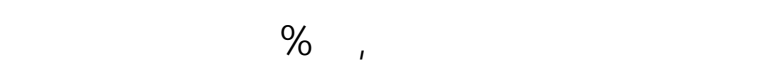

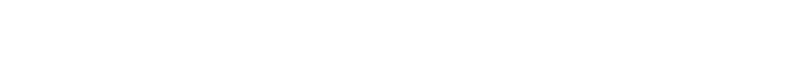

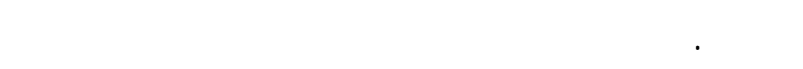
97,17\% الخضار والفلكهة قبل تناولها.

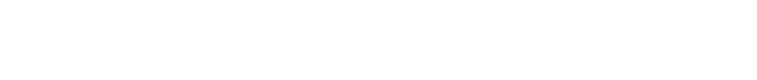

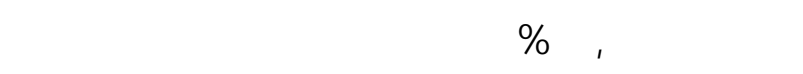

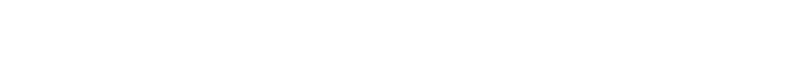

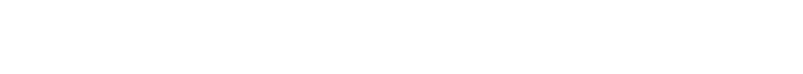

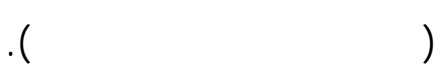

وأن سع, ال71\% لايتلكن من تاريخ الصلاحية الأغذية المعبلة والمغلفة فى حين تبلغ نسبة المبحوثلت اللاتى

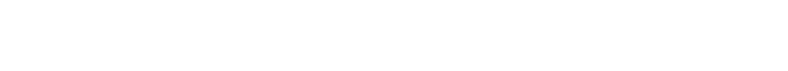

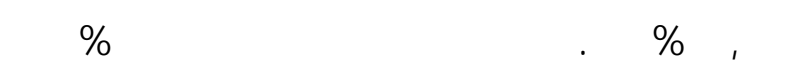

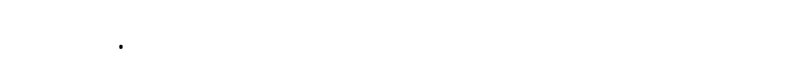

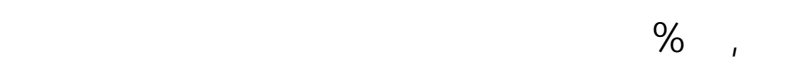
الثرراء بينما ققوم · ا\% منهن فتط بذك بشكل دائم وفيما يتعلق بتجنب شراء الأغذية المضف لها المواد الحلظة

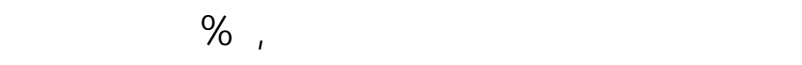
على عدم شراء الأغنية المضف المضلف المونف لهات مواد حلظة.

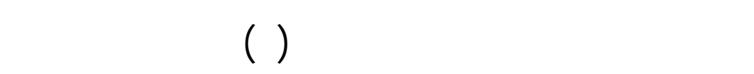

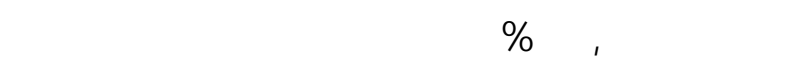

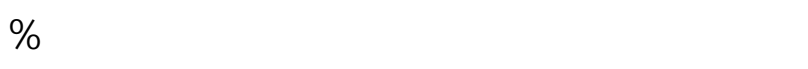

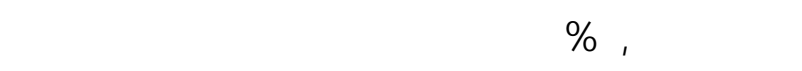
مابسة مرتقع.

\section{جدط ع. توزع المبحوثلت وقا الفيم الرقمية الدالة عل}

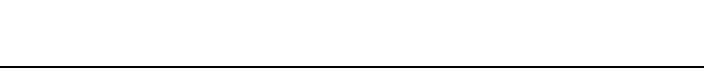

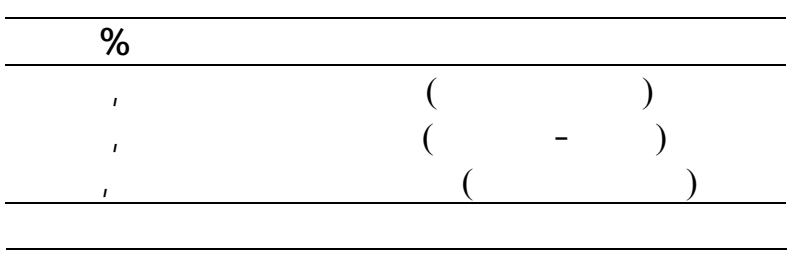
ويؤكد ذلك على مدى حلجة هـ -ؤلاء المبحوث لت للب ـرامج

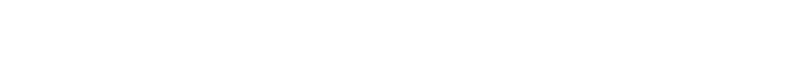




\begin{tabular}{|c|c|c|c|c|c|c|c|c|}
\hline & & & & & & | - |إعداد ر & 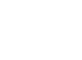 & مبحوثلت وقةا لممارساتهن \\
\hline & & $\mathrm{J}$ & & 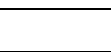 & & أ & & الممارسة \\
\hline$\%$ & عدد & $\%$ & عدב & $\%$ & عدد & $\%$ & عدد & \\
\hline $1 \cdots$ & $I \varepsilon$. & . & $\cdot$ & $r, 1 \varepsilon$ & $\mu$ & $9 \mathrm{~V}, \wedge 7$ & IrV & I - الحرص وإزالة الأتربة والقاذوروات والفية والفلكهة \\
\hline $1 \cdots$ & $I \varepsilon$. & $71, \varepsilon \mu$ & 17 & $\mu$ & $\varepsilon \Lambda$ & $\varepsilon, \varphi^{\prime}$ & 7 & 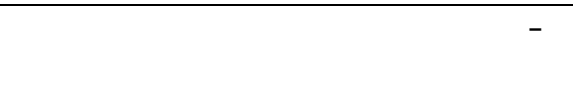 \\
\hline $1 \cdots$ & $1 \varepsilon$. & $\varepsilon, r q$ & 7 & $\mu \mathrm{V}, 1 \varepsilon$ & or & $0 \Lambda, 0 \mathrm{~V}$ & $\Lambda r$ & "َ - قع البيض الغليلن . النار لمدة لاثل عن 0 \\
\hline $1 \cdots$ & $1 \varepsilon$. & $\Lambda \mu, O \mathrm{~V}$ & $11 \mathrm{~V}$ & $10, \mathrm{~V} \mid$ & r & $\cdot, \mathrm{VI}$ & 1 & 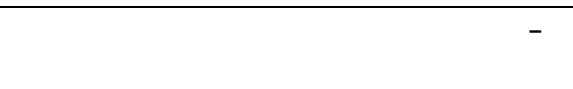 \\
\hline $1 \cdots$ & IE. & $\cdot, \mathrm{V})$ & 1 & $1, \varepsilon \mu$ & $r$ & $9 \mathrm{~V}, \wedge 7$ & $1 \mathrm{HV}$ & 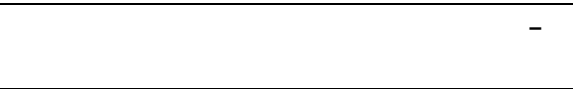 \\
\hline $1 \cdots$ & $I \varepsilon$. & $\mathrm{VV}, \wedge \mathrm{T}$ & 1.9 & $V, I \varepsilon$ & 1 . & 10 & rI & 7 - لطففاء النار بمجرد غليان اللبن \\
\hline $1 \cdots$ & IE. & $\mathrm{V} \wedge, 0 \mathrm{~V}$ & 11. & $r$. & $r \Lambda$ & $1, \varepsilon \mu$ & $r$ & V - لمتخده الزيت المقدوح حق تغير لونه . \\
\hline $1 \cdots$ & IE. & $r V, I \varepsilon$ & $\mu \wedge$ & $09, \mathrm{q}$ & $\Lambda \mu$ & $1 \%, 0 \mathrm{~V}$ & 19 & 1 - تسخن الخبز بوضعه على النار مبلثرة \\
\hline $1 \cdots$ & IE. & $\Lambda I, \varepsilon$ & $11 \varepsilon$ & $|r,| \varepsilon$ & IV & $7, \varepsilon{ }^{\mu}$ & 9 & 9 - الكضفاء بغسل حزمة الخس بحالها دون \\
\hline $1 \cdots$ & IE. & $7, \varepsilon \mu$ & 9 & $\mu r, I \varepsilon$ & عo & $71, \varepsilon \mu$ & 17 & 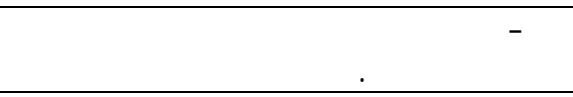 \\
\hline $1 \cdots$ & $\boldsymbol{I \varepsilon}$ & $\varepsilon, r \Lambda$ & 7 & $\mathrm{~V}, \Lambda \mathrm{T}$ & 11 & $\wedge \mathrm{V}, \wedge\urcorner$ & $\mu$ & 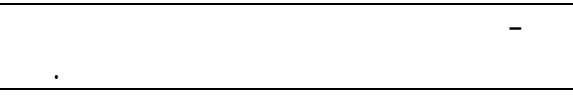 \\
\hline $1 \cdots$ & IE. & $\varepsilon 0, \mathrm{~V})$ & \rceil$\varepsilon$ & rq, rq & ا & ro & ro & rا - الخضروات كالملوخية. \\
\hline
\end{tabular}

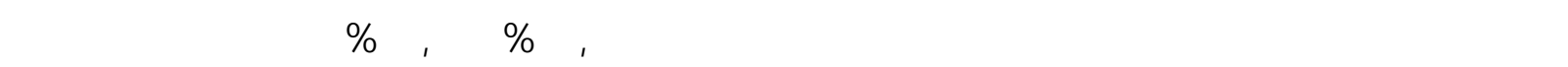

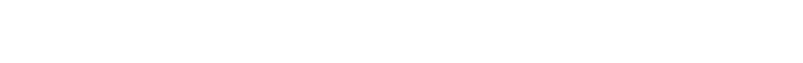

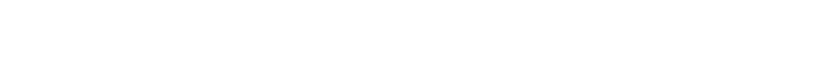

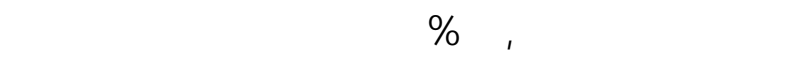

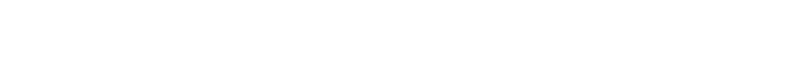
المواد اللسلمة للإنسان.

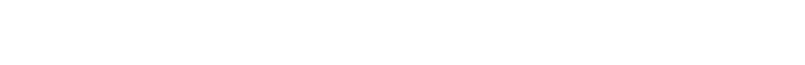

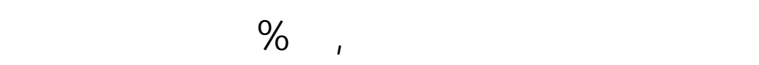

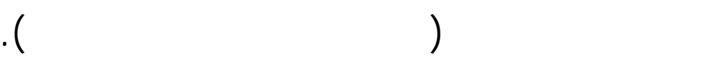

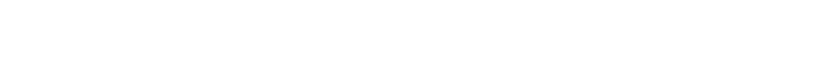

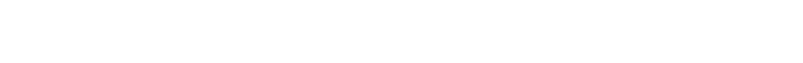

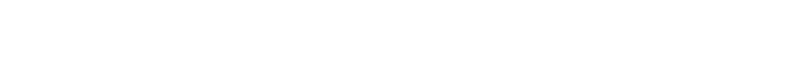

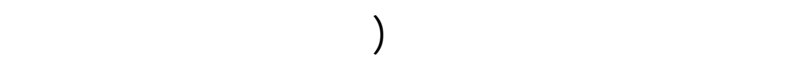

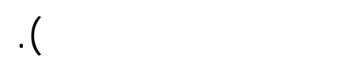

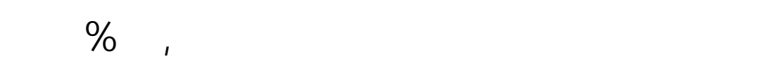

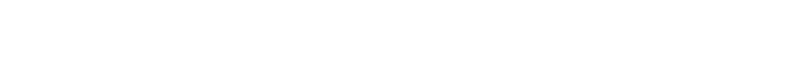

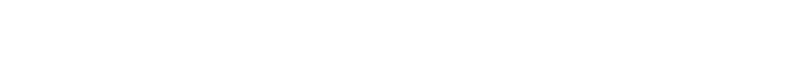

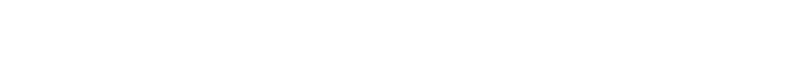

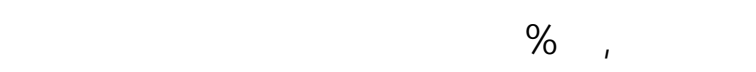
النار مبلاشرة وهاطوريقة خطيرة على صحة الإنسلن حيث يصلمب لحتراق لهب الغاز خروج مركبات كيميائية ضارة بالصحة ذات تاثيرات مسرطنة للخلايا يمتصها الخبز ومن الخيات فم تنظل الجهاز الهضم للانسان وتمتص عبر الدم الشيرين

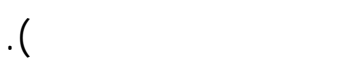

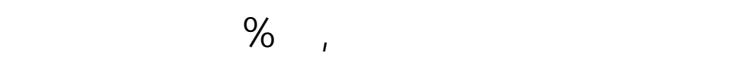

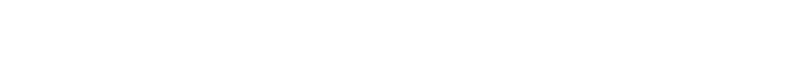
يقمن بقصيص الأوراق وغسلها بشكل صحبح.

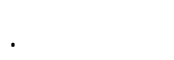




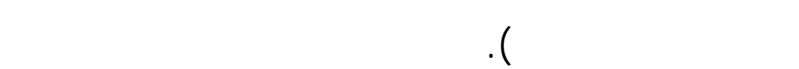

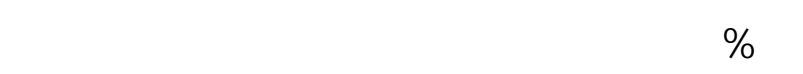
عبوات بلاستيكيةما يشل خطرا اوضررا بصحة الإنسلن

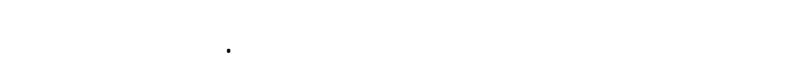
الغالبية الظمه منهن دائما بغلى اللبالنخ أوالملوخية البايتة

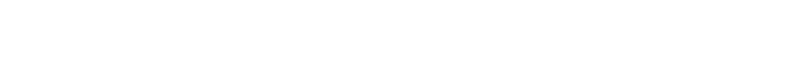

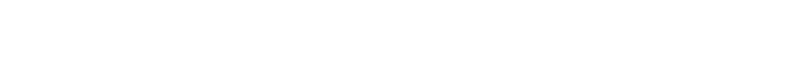

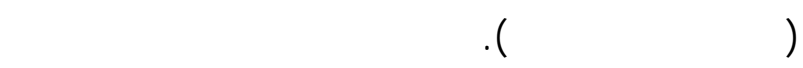

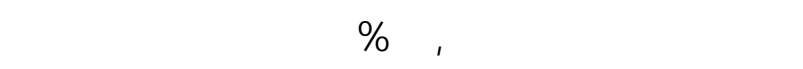

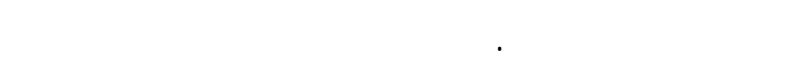

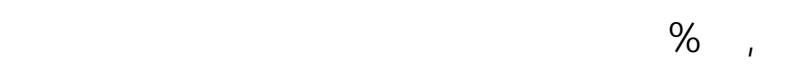

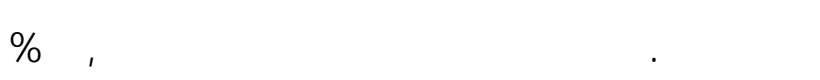

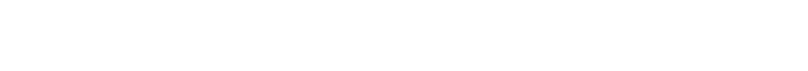

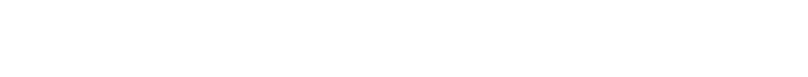

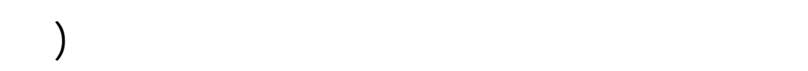

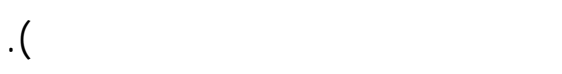

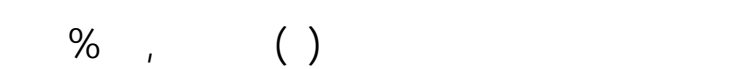

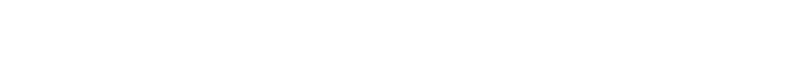

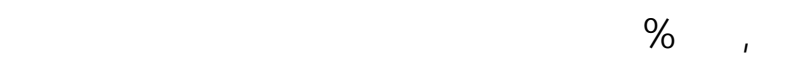
مما ييل على أنهن بحلجة إلى التدريب لتعديل ممارساتتهن

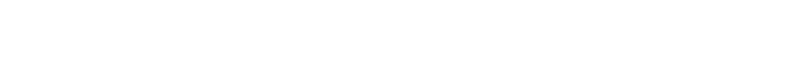

صحبح.

جدط7. توزيع المبحوثلت وقا الفيم الرقمية الدالة عل

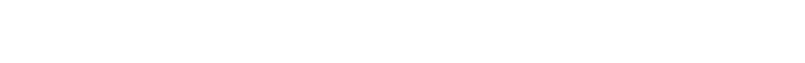
للالهـ

\begin{tabular}{|c|c|c|}
\hline$\%$ & عدد & ل \\
\hline $0, \cdots$ & $\mathrm{V}$ & منغفض( (أل من Vادرجة) \\
\hline $0 \wedge, 0 \vee$ & $\Lambda \mu$ & sub (من IV - IV درجة) \\
\hline$\mu$ & 01 & قفع (لكثر من آكررجة ) \\
\hline $1 \cdots$ & $1 \varepsilon$. & إجمالd \\
\hline
\end{tabular}

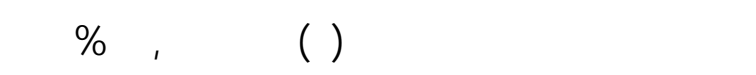
المبحوثلت لايستخدن أولف الألومنيوه في حظظ الغذاء

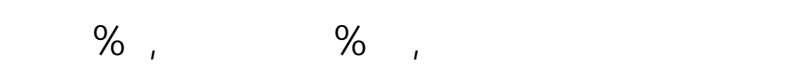
دأم وهـ ممابسة خطائة ظرا لفاعل الألومنيوم مع الغذاء

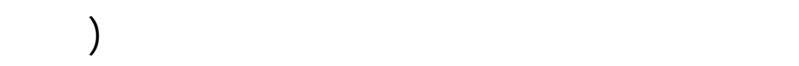

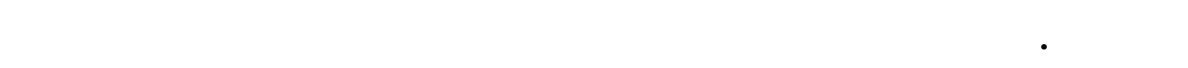

\begin{tabular}{|c|c|c|c|c|c|c|c|c|}
\hline \multicolumn{2}{|c|}{ الإجمالل } & \multicolumn{2}{|c|}{ لَبدا } & \multicolumn{2}{|c|}{ الَّيلنا } & \multicolumn{2}{|c|}{ طائما } & \multirow[t]{2}{*}{ الممارسة } \\
\hline$\%$ & عدد & $\%$ & عدد & $\%$ & عدد & $\%$ & عدנ & \\
\hline $1 \cdots$ & $I \varepsilon$. & $09, \mu$. & $\Lambda \mu^{\mu}$ & rr, 10 & $\varepsilon 7$ & $\mathrm{~V}, \mathrm{AO}$ & 11 & الألومنفا بالطعلم الهطهى فى الثلاجة فى أولف \\
\hline 1.. & $1 \varepsilon$. & $r \wedge, O V$ & $\varepsilon$. & $00, \cdot \cdots$ & VV & $17, \varepsilon{ }^{\mu}$ & $\mu^{\mu}$ & 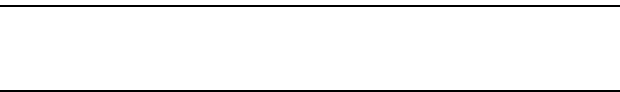 \\
\hline $1 \cdots$ & IE. & $r, \Lambda 7$ & $\varepsilon$ & $0, \cdots$ & $\mathrm{V}$ & १५,। & $1 \% 9$ & 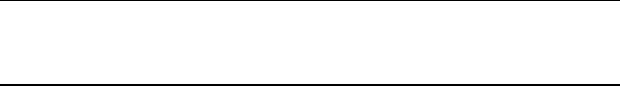 \\
\hline 1... & $1 \varepsilon$. & $r, \Lambda 7$ & 11 & $\cdot \cdots$ & $\varepsilon r$ & $0 \mathrm{~V}, 1 \varepsilon$ & $\Lambda \cdot$ & تشخين البيض المتقى من يومسابق وتناوله \\
\hline $1 \cdots$ & $1 \varepsilon$. & $9 \cdot, \mathrm{VI}$ & ITV & $0, \cdots$ & $\mathrm{V}$ & $\varepsilon, \mathrm{rq}$ & 7 & ولحدم الطعلم لأفراد الأنسرة او الأبناء فىطق \\
\hline 1. & $1 \varepsilon$. & & 14 & $10, \cdot \cdot$ & rI & $\vee\urcorner, \varepsilon \eta^{\mu}$ & $1 \cdot V$ & إعالة تصنخن الطعلم المبوخ ليصبح دافئا فظط \\
\hline 1. & IE. & rY,AV & ६१ & $r Y, A V$ & r & $\varepsilon r, 1)^{\mu}$ & 09 & 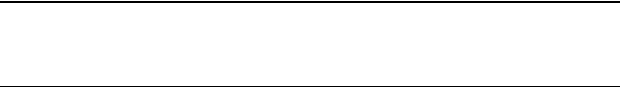 \\
\hline $1 \cdots$ & $1 \varepsilon$. & $00, \cdot \cdots$ & & $00, \cdot \cdot$ & VV & $r \cdot, \mathrm{VI}$ & rq & 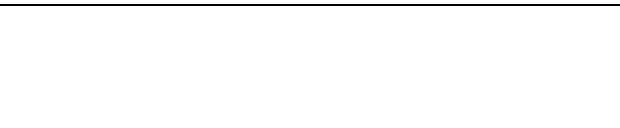 \\
\hline 1. & $1 \varepsilon$. & $1 \cdot, \cdot$ & $\because$ & 1.. & $1 \varepsilon$ & $9 \cdot, \cdot \cdots$ & 147 & 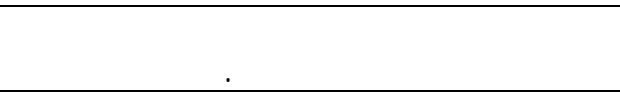 \\
\hline
\end{tabular}




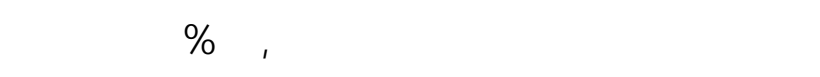

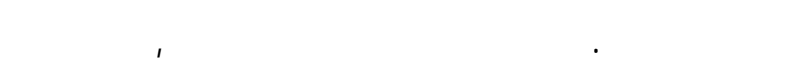

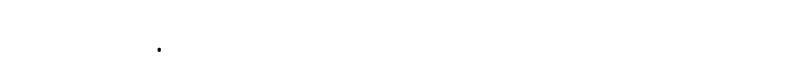

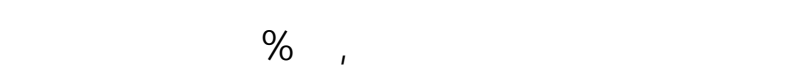

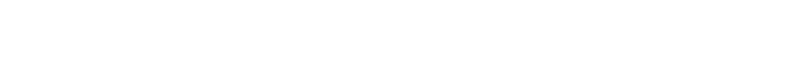

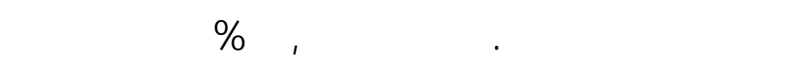

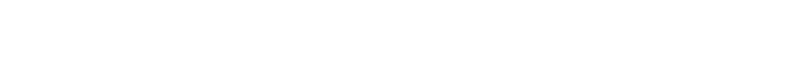

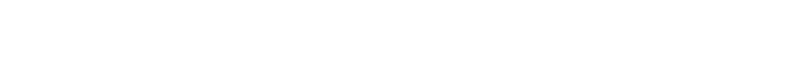

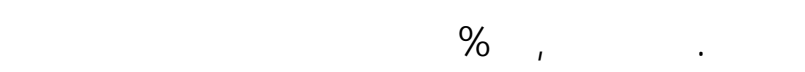

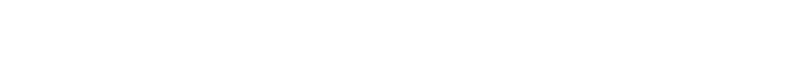

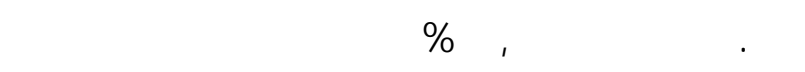

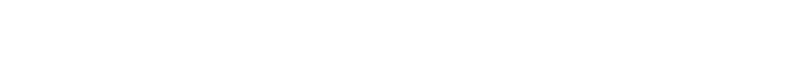
الإصابة بالزكلم والإسهال حت لايكون ذلكسببا فى حدوث

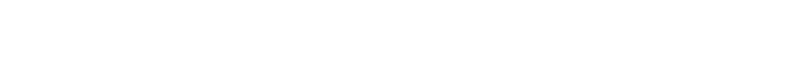
العدوى إلى أفراد لمسرتها.

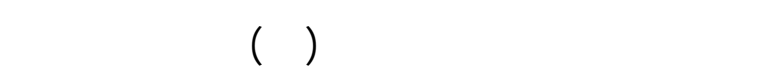

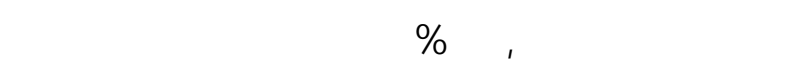

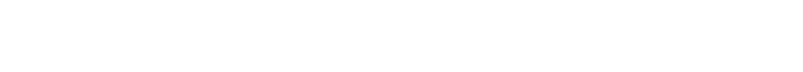
المنخ،
وفيما يتعلق بعدم ترك الطعلم على درجة حرارة الغرفة

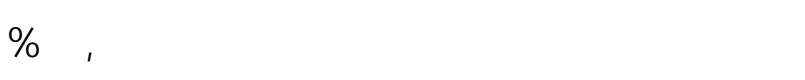

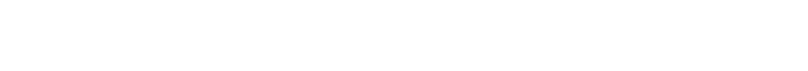

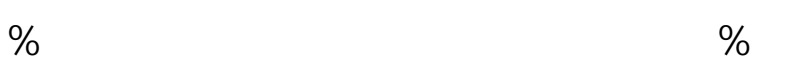

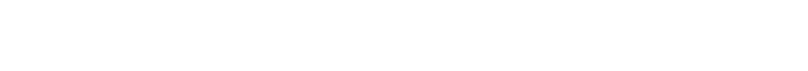
أوخارج الثلاجة لمنع تلوثه بالأتربة والهشرات.

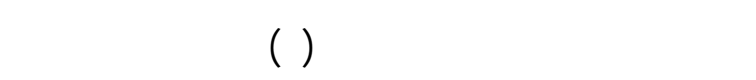

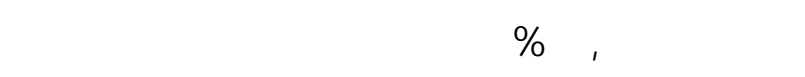

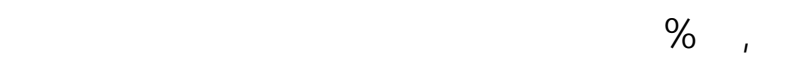

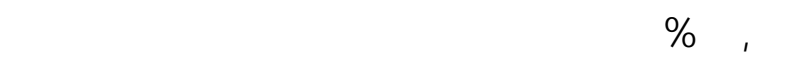

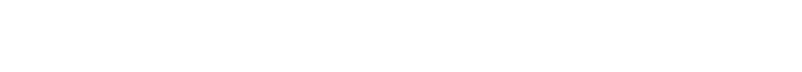

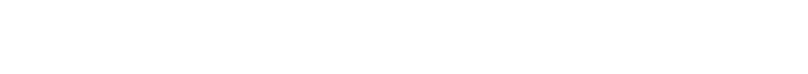
الطعل أثناء الإعداد والطهي.

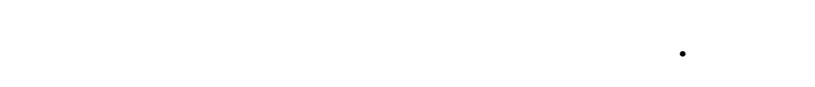

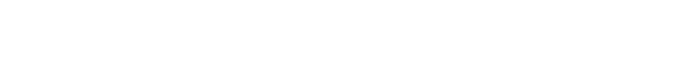

\begin{tabular}{|c|c|c|}
\hline$\%$ & عدد & الفئلت \\
\hline $10, V Y$ & $r \mu$ & منغضض(ألم من س ادرجة) \\
\hline $7 \cdot, \mathrm{vi}$ & 10 & متوسط (من س| | -10 درجة ) \\
\hline $\mathrm{r \mu}, \mathrm{OV}$ & س & مرتقع (لكثر منام درجة ) \\
\hline $1 \ldots$ & IE. & إجمالى \\
\hline
\end{tabular}

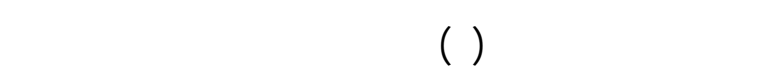

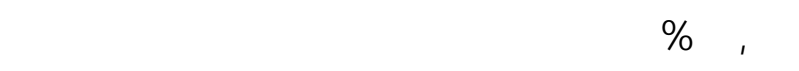

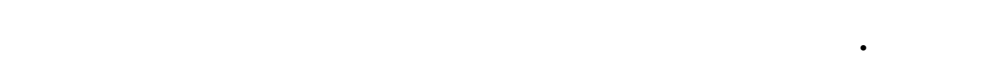

\begin{tabular}{|c|c|c|c|c|c|c|c|c|c|}
\hline \multicolumn{2}{|c|}{ لالحمال } & \multicolumn{2}{|c|}{ ألدا } & \multicolumn{2}{|c|}{ أحيلا } & \multicolumn{2}{|c|}{ כأما } & \multirow{2}{*}{\multicolumn{2}{|c|}{ الممارسة }} \\
\hline$\%$ & عدב & $\%$ & عבد & $\%$ & عدد & $\%$ & عدב & & \\
\hline $1 \cdots$ & $1 \varepsilon$. & $r\urcorner, \varepsilon \mu$ & $\mu V$ & Or, $1 \varepsilon$ & $V^{\mu}$ & $\Gamma I, \varepsilon \mu$ & $\mu$. & ـ تظية جروح وقروح اليد بطاء محكم & 1 \\
\hline $1 \cdots$ & $1 \varepsilon$. & $r 0, \mathrm{~V}$ & " 7 & $0 \cdot, \mathrm{VY}$ & VI & $\Gamma \mu, 0 \mathrm{~V}$ & $\mu \mu$ & والأساور عند البدء فى تحضير الطعلم & $r$ \\
\hline $1 \cdots$ & $1 \varepsilon$. & $1 \cdot, \mathrm{VI}$ & 10 & $1 Y, \Lambda 7$ & 11 & $\mathrm{~V} 7, \varepsilon \mu$ & $\mathrm{I} \cdot \mathrm{V}$ & الاهتمل بتغطية الشعر بنطاء ظف أثناءطهي & $\mu$ \\
\hline $1 \cdots$ & $1 \varepsilon$. & $\cdot, \cdot$ & $\cdot$ & $\mu V, \Lambda 7$ & Or & $7 \pi, 1 \varepsilon$ & $\Lambda \mathrm{V}$ & الطعرص وقل على تنكرار غسل الأتيدى قل وإثناء إعداد & $\varepsilon$ \\
\hline $1 \cdots$ & $1 \varepsilon$. & 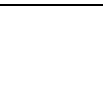 & . & $\mu, \mu^{\mu}$ & $\varepsilon \Lambda$ & $70, \mathrm{~V})$ & $9 \pi$ & والصابع اليد ععد ذلك الفم والأف أثناء الطس وغسلها بالماء & 0 \\
\hline $1 \cdots$ & $I \varepsilon$. & $\therefore$ & . & $\mu\urcorner, \varepsilon \mu$ & 01 & $7 \%, 0 \mathrm{~V}$ & $\Lambda 9$ & 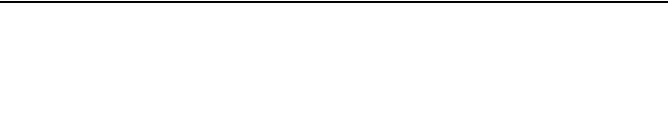 & 7 \\
\hline
\end{tabular}


اوضحت النتائج بجدول(1) أن مغلم المبحوثلت

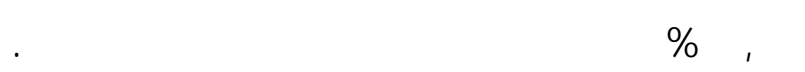

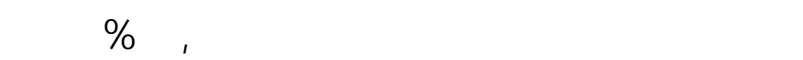
بلستخدلم المبيد الهشرى للقضاء على الهشرات أثناء إعداد

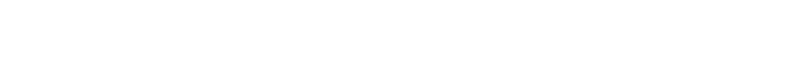

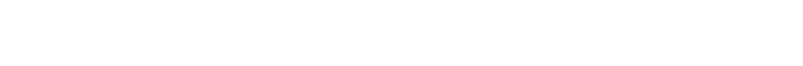

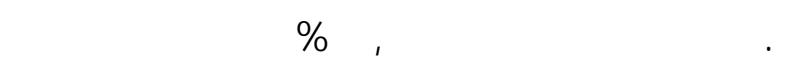

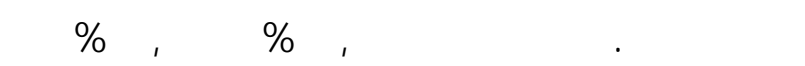

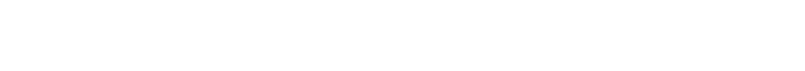

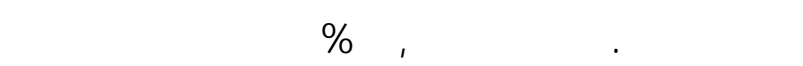
وظهير دواليب الطبخ بشكل دأم.

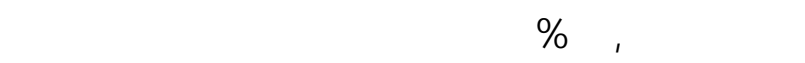
المرتقع مما يل على أن نصف المبحوثلت نقريبا بحلج فئة

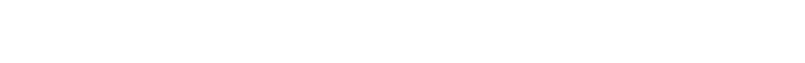

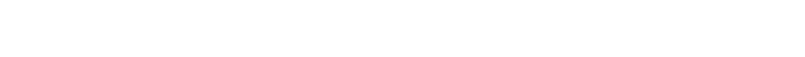
صححة

جطر · 1. توزع المبحوثلت وقا الفيم الرقمية الدالة عل

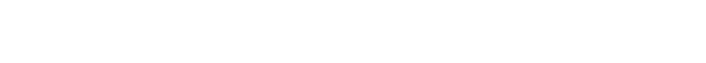

\begin{tabular}{|c|c|c|}
\hline$\%$ & عנد & الهئلت \\
\hline $0, \mathrm{VI}$ & $\Lambda$ & منخفض (أقلمن سب بدرجة) \\
\hline$\varepsilon \wedge, 0 \wedge$ & $7 \Lambda$ & متووط (من سץ - اس درجة) \\
\hline$\varepsilon 0, \mathrm{~V}$ & \rceil$\varepsilon$ & مرققع (أكثر من اس درجة) \\
\hline $1 \cdots$ & IE. & الجمالى \\
\hline
\end{tabular}

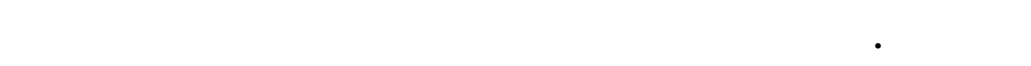

\begin{tabular}{|c|c|c|c|c|c|c|c|c|c|}
\hline \multicolumn{2}{|c|}{ لإجمال } & \multicolumn{2}{|c|}{ لَبدا } & \multicolumn{2}{|c|}{ ألحيلنا } & \multicolumn{2}{|c|}{ ) (أما } & \multirow[t]{2}{*}{ العبارت } & \multirow[t]{2}{*}{ م } \\
\hline$\%$ & عدد & $\%$ & عدد & $\%$ & عدב & $\%$ & عدב & & \\
\hline $1 \cdots$ & IE. & $7, \varepsilon \mu$ & 9 & $\mid \varepsilon, r \wedge$ & $r \cdot$ & V৭, rq & 111 & منع الحيوانت الأليفة قدر الإمكان من نخول & 1 \\
\hline $1 \cdots$ & $1 \varepsilon$. & $Y V, 07$ & rq & $r \cdot, \mathrm{V})$ & rq & $01, \varepsilon \mu$ & Vr & إعداد الطعد المبيد الهشرى لقل الهشرات أثناء & $r$ \\
\hline $1 \cdots$ & $1 \varepsilon$. & . & . & $1 Y, \Lambda 7$ & 11 & $\Lambda V, 1 \varepsilon$ & ITr & ألتخلص من القملمة يشكل يومِ (بانقلم ). & $\mu$ \\
\hline $1 \cdots$ & $\mid \varepsilon$. & 1 . & $1 \varepsilon$ & & $\Lambda 7$ & $0 \wedge, 0 \mathrm{~V}$ & $\varepsilon$. & وأرضرضية المليخ . & $\varepsilon$ \\
\hline $1 \cdots$ & IE. & re,rq & $\mu \varepsilon$ & 00 & VV & $r \cdot, V I$ & rq & الطعصديص ملعقة لاطهى ولخرى لتذوق & 0 \\
\hline $1 \cdots$ & $\mid \varepsilon$. & $\cdot, \mathrm{VI}$ & 1 & $r \cdot, V r$ & rq & $\mathrm{V} \Lambda, 0 \mathrm{~V}$ & $11 \cdot$ & الحرص على تظظف وظهير المطقية & 7 \\
\hline $1 \cdots$ & $1 \varepsilon$. & $\cdot, \mathrm{VI}$ & 1 & Tד, & $\varepsilon 7$ & $77, \varepsilon{ }^{\mu}$ & $9 \mu$ & 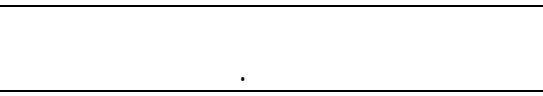 & V \\
\hline $1 \cdots$ & $\mid \varepsilon$. & $O V, \Lambda\rceil$ & 11 & $\mu \wedge, 0 \vee$ & IV & $r ו, 1 \varepsilon$ & IV & 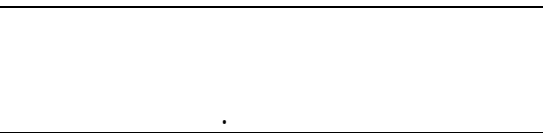 & $\Lambda$ \\
\hline $1 \cdots$ & $\mid \varepsilon$. & $\cdot, \mathrm{VI}$ & 1 & 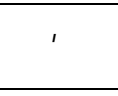 & $\Lambda \Lambda$ & $7 \cdot, \mathrm{VT}$ & 10 & 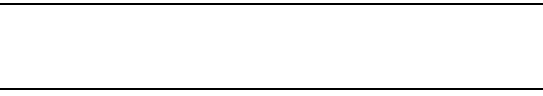 & 9 \\
\hline $1 \ldots$ & $1 \varepsilon$. & $\varepsilon, \Gamma \wedge$ & 7 & $7 \mu, 0 \mathrm{~V}$ & $\mu$ & $7 \pi, \Lambda 7$ & $\Lambda \Lambda$ & الإهتمل بتعقيم خزلن الميل بشكل دورى. & 1. \\
\hline 1 . & $\mid \varepsilon$. & $1 \cdots$ & $1 \varepsilon$ & $\varepsilon V, \Lambda\rceil$ & १५ & $r\rceil, \varepsilon \mu$ & $\mu \mathrm{V}$ & 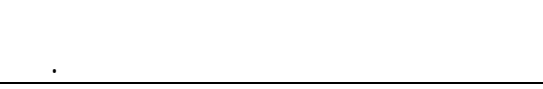 & 11 \\
\hline $1 \cdots$ & $\mid \varepsilon$. & $r \Lambda, O V$ & $\varepsilon$. & $\mu$ & ر & Yr,OV & ru & تقنيم الحوض اللحوب والدولجن والكلور بعد الآتته باء & 14 \\
\hline $1 \cdots$ & $\mid \varepsilon$. & $r, I \varepsilon$ & $\mu$ & $V, 1 \varepsilon$ & $9 \mu$ & $77, \varepsilon \mu$ & $9 \mu$ & 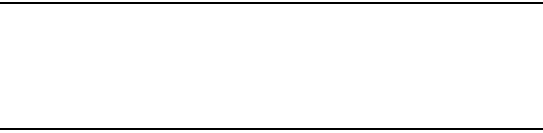 & $1 \mu$ \\
\hline $1 \cdots$ & $\mid \varepsilon$. & $|0, \mathrm{~V}|$ & r & $V, 1 \varepsilon$ & 1 . & $V V, 10$ & $1 \cdot 1$ & الألتنهاءعن بشطف اللحوف المفرمة فتط بالماء بعد & $1 \varepsilon$ \\
\hline
\end{tabular}


جنط Ir. توزيع المجحوثلت وقا الفيم الرقمية الدالة علل

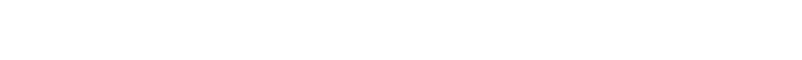

من النالوث

\begin{tabular}{|c|c|c|}
\hline$\%$ & عدב & الفئلت \\
\hline$\backslash \Lambda, \mathrm{VO}$ & r & فض(آلّلمن سج درجة) \\
\hline $\mathrm{OH}^{\mathrm{O}} \mathrm{OV}$ & vo & وسط (من سو -7 - أدرجة ) \\
\hline$Y V, \Lambda T$ & м & لقعَع (لكثرمن 7· ادرجة ) \\
\hline 1 & I & \\
\hline
\end{tabular}

يتضح من النتائج الوارة بجدول (سار) ان هنك علافة

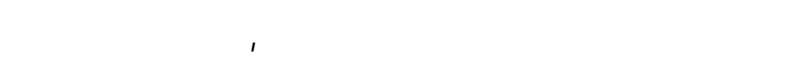

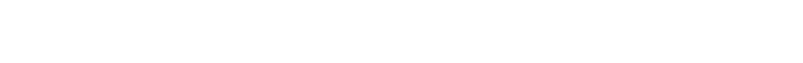

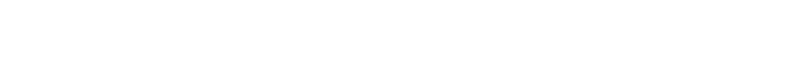

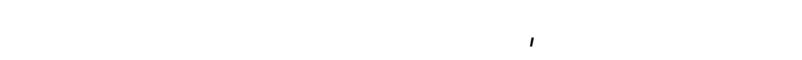

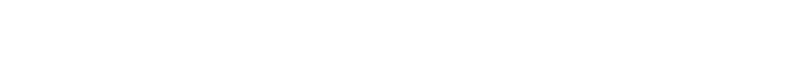

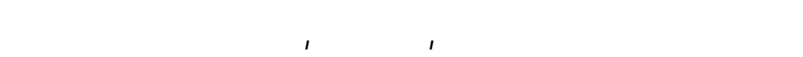

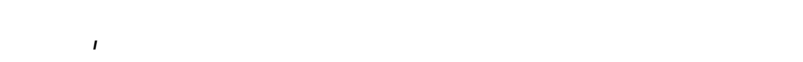

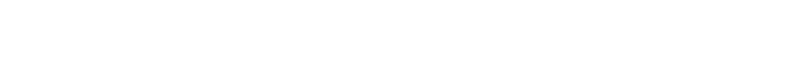

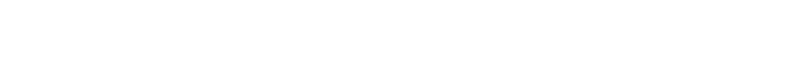

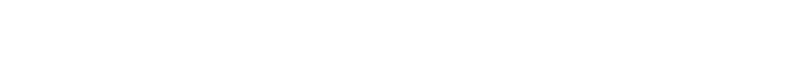
مستل ولحد وبين المتغير التايع وكلتت قيم معال الارتبطاط

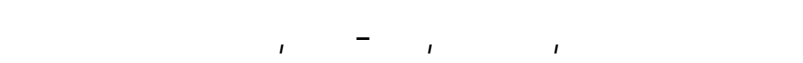

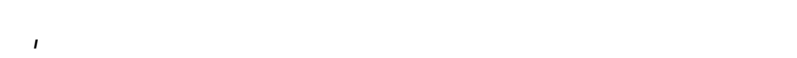

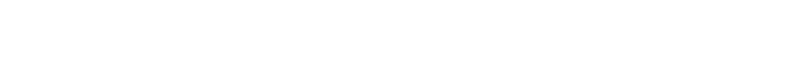

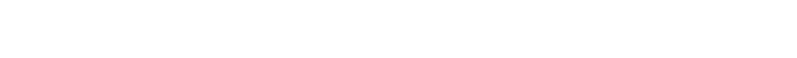

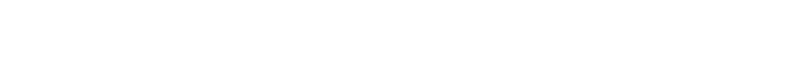

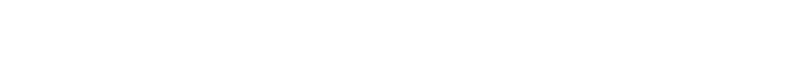

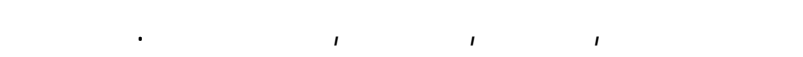

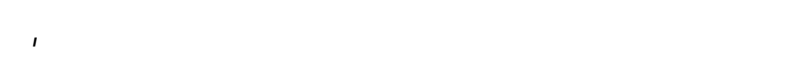

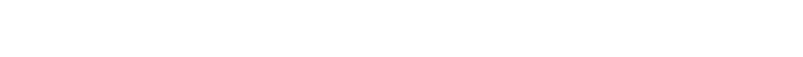

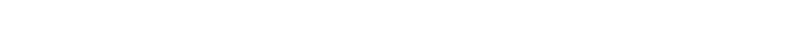
معلمل الارتبط البسط لبيرسون 7 اع, ، كما توجد علاقة

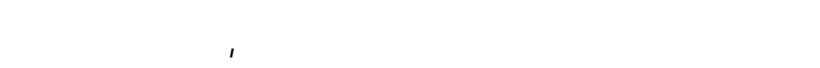

أما عن لمتخدلم الماء والصابون والمطهرات فى تقظف الثلاجة فإن مظم المبحوثلت \%V^,OV يداومن على ذلك. أما بالنبة لتخصيص ألواح نظطيع وسكلكن خالصنة

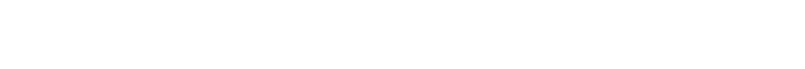

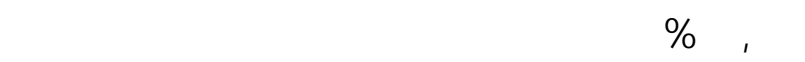

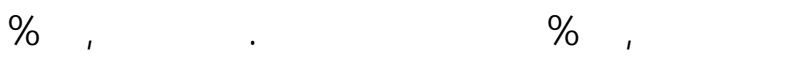

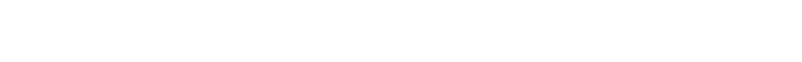

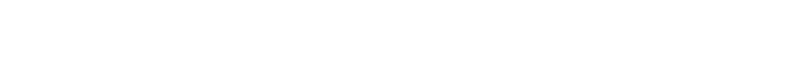

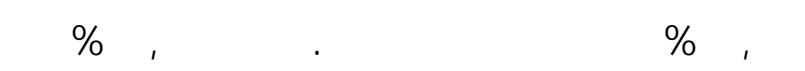
المبحوثت على تعقيم خزان الميل بشكل دورى فى حالة المان وجود خزان الميله.

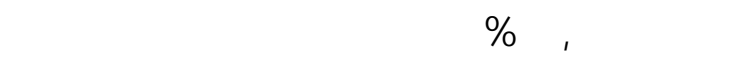

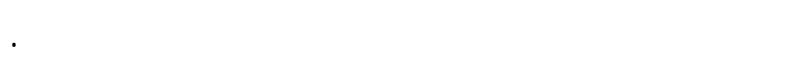

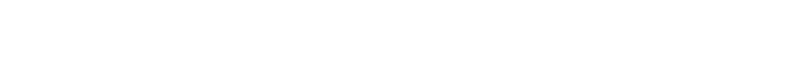

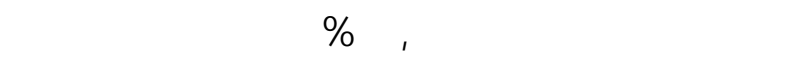

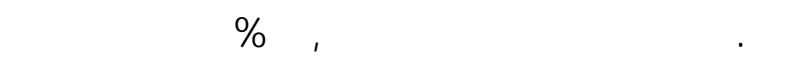

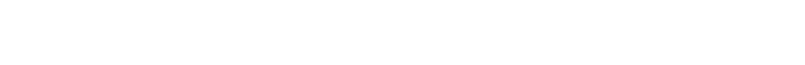

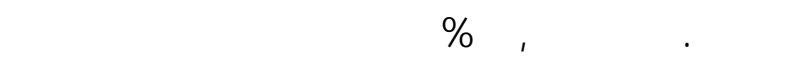

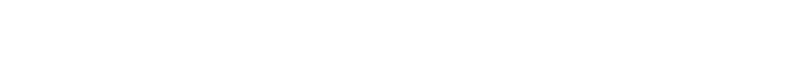
وقل لستخدامها لفرم الخضروات مرة لخغرى.

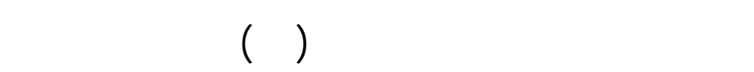
المبحوثلت \%0r,OV قعن في فئة المستوى المتوبط بينما

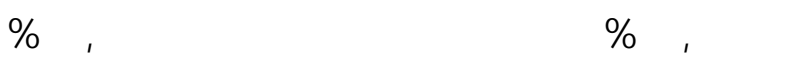
فى فئة المستوى المنخفض. أى أن غالبية المبحوثات

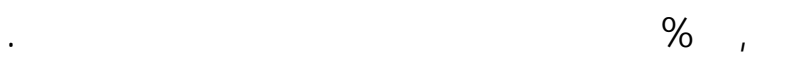

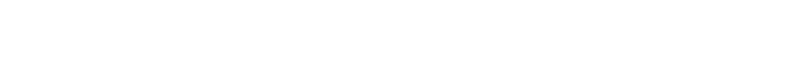

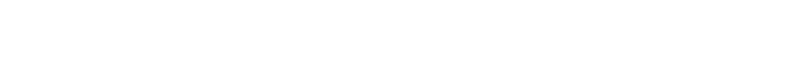
لمسبل التلوث مما ينعكس بدوره على ممارساتهن اللسليمة والصحيحة وبالتالى الحفظظ على صحة الأسرة بصفة خاصة والمجتمع بصفة علمة والارنقاء بهما. 
بين كل من مستوى تعليم المبحوثة ومستوى تعليم الـ ـزوج كمتغيرين مستقلن وبين المتغير التاع وكانت قيمت معلمل الارتبط على الترتيب 019, · ،

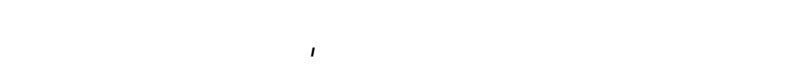

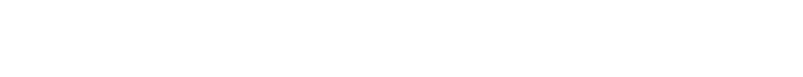

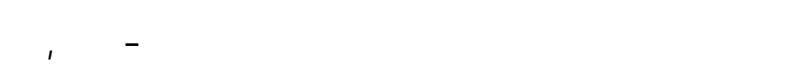
و -ع ه . . • على التواله.

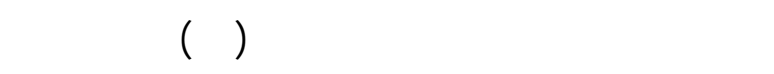

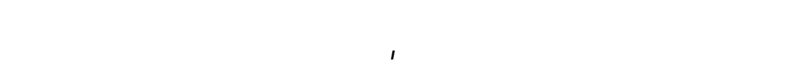
كمتغير مستل وبين كل من مماسلت التداول عند الثرراء، ومماسست الإعداد والطه، وممارست التداول والحظظ

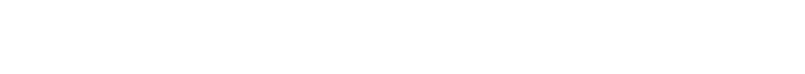
ومماسبت بيئة المطخ كمتغير تابع، وكانت قيم مربع كاى ولى

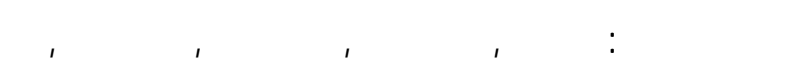

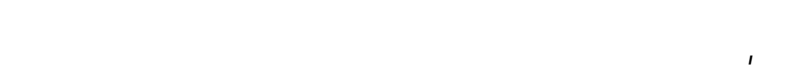
معنوية عند مستوى 0 . . بين نوع الأسرة كمتغير مسنظل

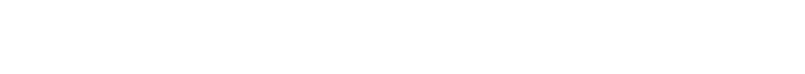

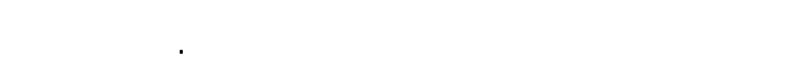

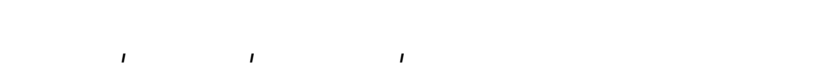
^ع,ع، وعی,
الأسرة كمتغير مسفل وكلن ـت قيم ـة معله لل الارتب لطا

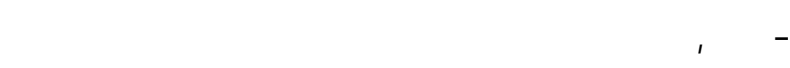

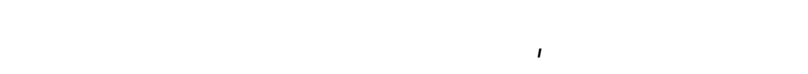
تعليم الزوج كمتغيرات مستقلة وبين المتغير التايع ، وكانت

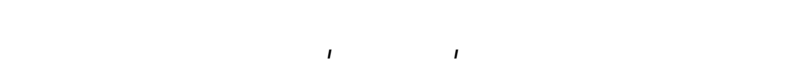

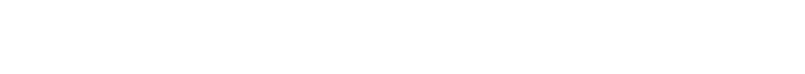

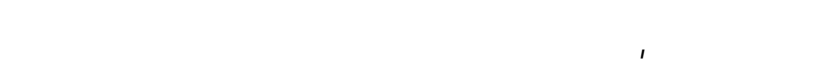

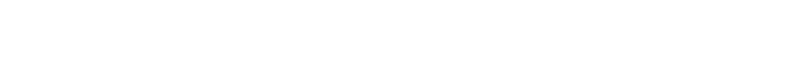

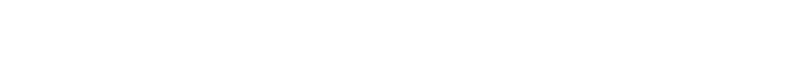

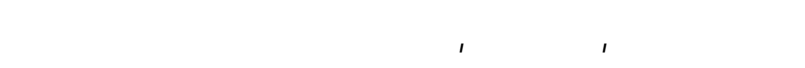

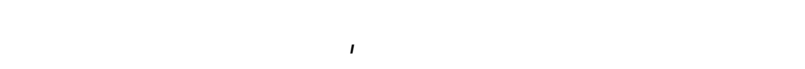
وهو درجة الافتاح الحضرى وبين المتغير التايع وكان تـ

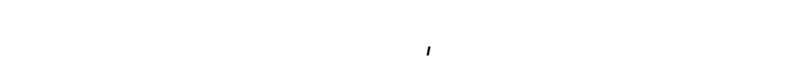

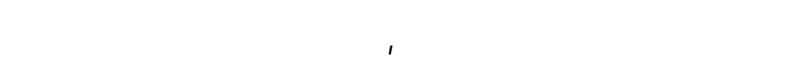

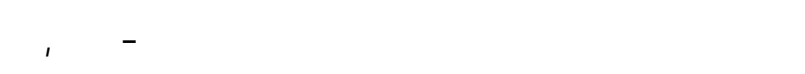
ووجود علاقة ارتبطيةسالبة عند مـ ستوى معنوي ة 0 . , .

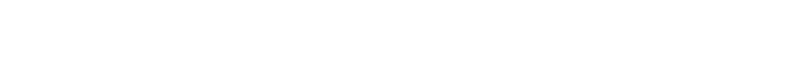

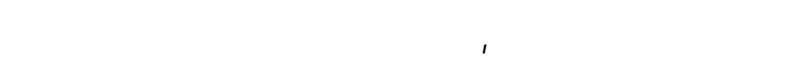

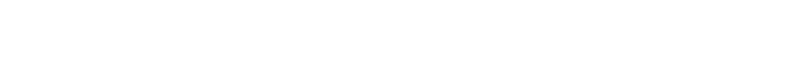

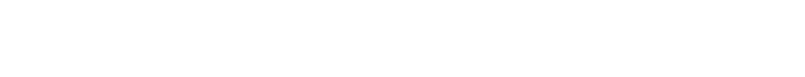

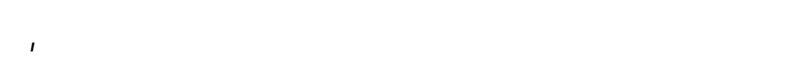

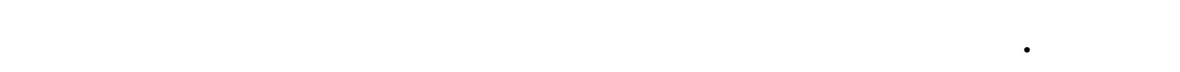

\begin{tabular}{|c|c|c|c|c|c|c|}
\hline ألجمالل & بيئة الملبخ & الشخالهة & التبد اللارب واله & 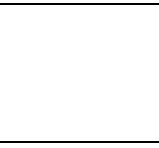 & عمالتسلك & المتغيرات المسقلة \\
\hline$* * \cdot, \mu \cdot 7-$ & $* *, r \mathrm{rV}-$ & *., ro & $\cdot, \mid{ }^{\mu} \mathrm{V}$ & - זOE- & ·, r। T- & \\
\hline$* * .$, . & $* \cdot, r \mid \cdot-$ & $* * ., O \Lambda-$ & 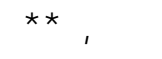 & $\cdot, \cdot \mathrm{V} \mu$ & $\cdot, \cdot r o-$ & عدد أفراد الأسرة \\
\hline$\cdot, \cdot \mathrm{r \Lambda}$ & $\cdot, \cdot \varepsilon r-$ & $\cdot$, ro & $\cdot, I \mu V$ & $\cdot 1 \cdot 0-$ & $\cdot, 11 \mu$ & 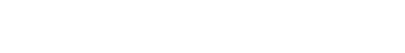 \\
\hline$* * \cdot, 0 \wedge 9$ & **. , EYV & **., & $* * \cdot, \mu r V$ & $* * ., \mu ו$ & $* * ., 001$ & مستوى تعليم المبحوثة \\
\hline$* * .$, * & **. ז & $* \cdot, \backslash \wedge$ & **., זrA & **., roV & $* ., \mu\urcorner 0$ & مستوى تعليم الزوج \\
\hline$\cdot, \cdot 9 \varepsilon-$ & - & $\cdot, .01$ & $\cdot, \varepsilon r-\cdot$ & $\cdot, \cdot \wedge 1$ & $\cdot, \cdot 11$ & تعدد مصادر المعلومات \\
\hline - & $* \cdot, 179$ & $\cdot, \cdot 01$ & **., rعץ & $\cdot, \cdot \mu$ & $\cdot, \cdot 17-$ & درجة الافتاح الحضرى \\
\hline • ( & $\cdot, \varepsilon 77$ & · •, ( & $\cdot$ ש & $\cdot, 1 \varepsilon$. & $\cdot, 109-$ & المشاركةالاجتماعية غيرالرسمية \\
\hline
\end{tabular}




\section{جدط عا. الملفلت الارتبللية بين المتغيرل المسقلة الومفيةالمدروسة والمتغير التلع بلستخدالممريع كلى}

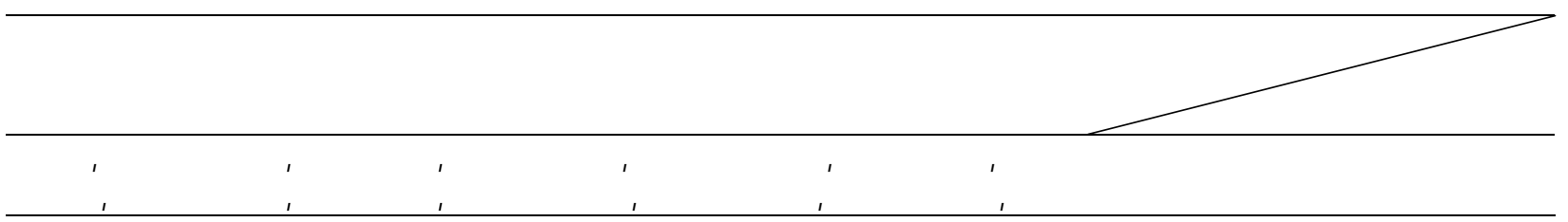

- ضرورة فعل دور الجهاز الإشادى فى مجل الغ ـاء ذاء

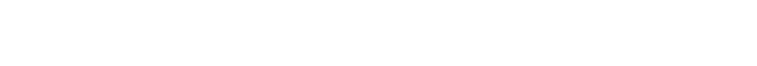

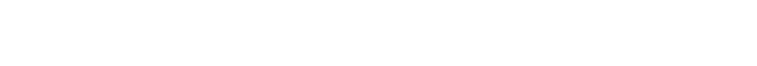

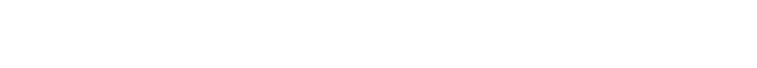

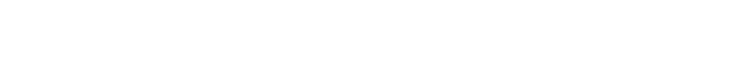
والمستهلاك وحمايتها من الملوثت المختلفة بهوف فقلها للاريفيت مما يؤنى إلى زيادوعيهن المعرفى الغ ذائى الفئي وإلمسابهن للسلوكيلت الصحيحة.

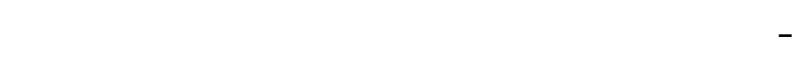

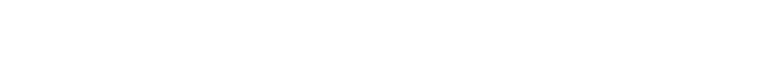
للأسرهن فى القرى لتوعيتهن بالتعلمل مع الغذاء بـ بشكل صجى وسليم. - الاسفاة من الدرلسات المختلفة فـ مجل الغذاء والتغذي مة

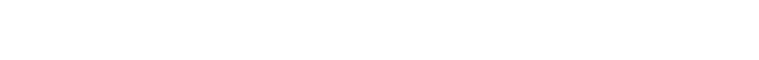

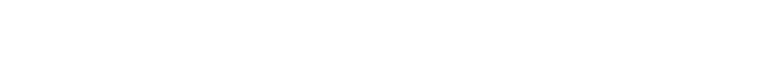

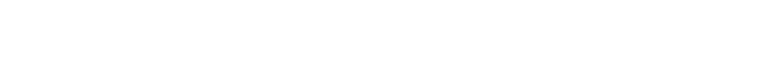

$$
\text { والتدريبية. }
$$

\section{الم ـراججع}

المركز العربق للتغذيةج·r، الإشادات الغذائية الأمريكية، المنامة، مملكة البحرين.

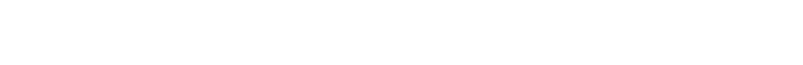

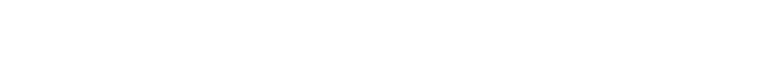
قرى بنجر اللسكر بمحلظة الإسكندرية، المجلة المصرية اللبحوث الزراعية، المجلد الثالث والثمانون، العدد الرليع،

ص: 19191919
وفيما ينعلق بالعلاقة ين عمل المبحوثة، ونوع الأسدرة

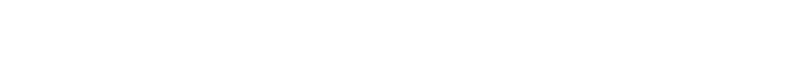
المتعلقة بالحفظ على الغذاء من التلوث عند مستوى معنوية

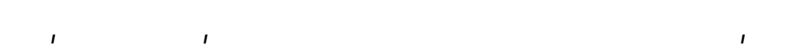
على التوالى وبهذه النتيجة فإننا قبل الفرض الإنبل الإحصائى بأنه

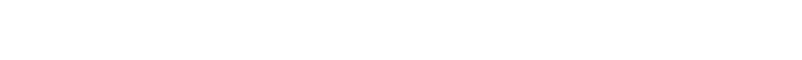

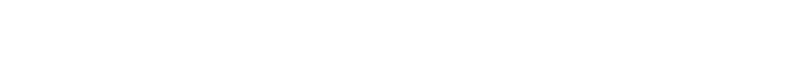
مجل الهغظ على الغذاءمن التلوث.

\section{التوصيلت}

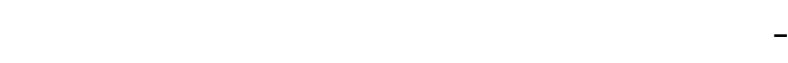

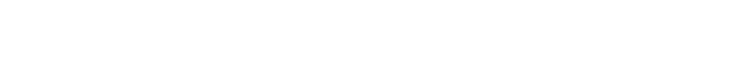

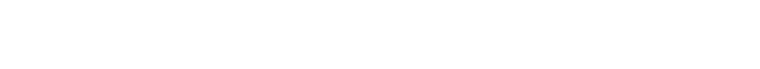
والمنظ واللستهلاك.

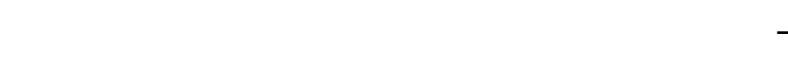

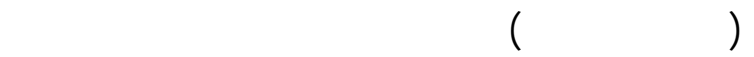

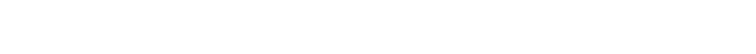
ششكل آمن وكفية الحغظظ عليه من التلوث أثناء النداول والإعداد والطهى والهظ والمستهلية الماك.

- ضرورة التعاون بين المرلكز البحثية ووزارة الزراء هة

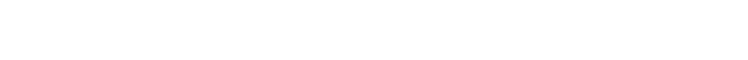
ودورات تدريبية وووش عمل للريفيت بمرلكز التنمي ـة الريفية والمرلكز والوحدات الصحية بالقرى تهرف إلـ قى

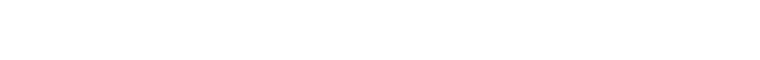
الطررق الصحية الصحيحة وللسليمة للتعلمل مع الغ ذاء

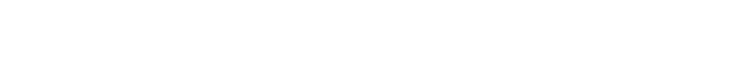

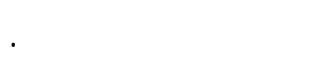


عبد الرحمن عبيد المصقر، زكريا عبد القادر خنجى، V.r. V. المماسات المتعقة بظلفة الطبخ وتداول وتحضير الطعلم عند النساء فى مملكة البحرين، المجلة العربية للغذاء والتغذية

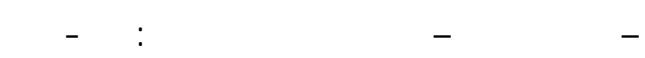
عبد المنعم محمد عبد الرحمن، عبد العل عاببن على عبد

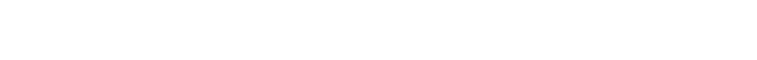

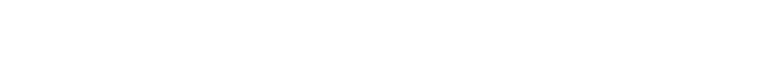

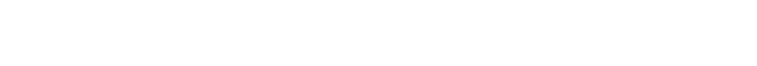
الثالث،: باص: ro-10 عزة عبد الكريم الجزار II إr، معرفة الريفيلت بالتوصيات

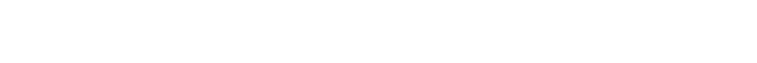

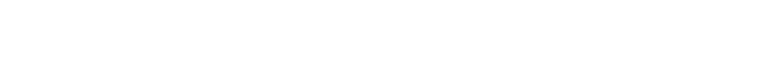

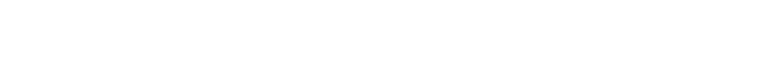

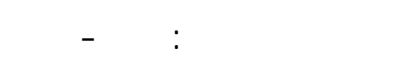

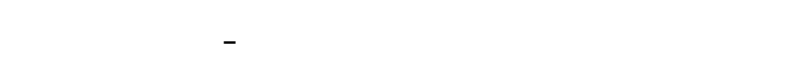
الخلبج، المجلة العربية للغذاء والتغنية ،المؤتمر العربه الثالف الغنية

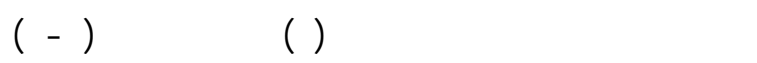

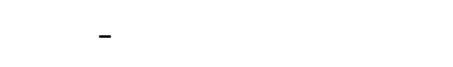

محمد هسيب رجب، 199V، مفهوم سلامة الغذاء وجوته،

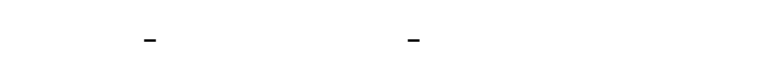

$$
\text { النترنلثيونل للنثر والطباعة. بيروت - لبنان. }
$$

نيفين مصطفى حلظ، ناصر البراهيم الصاوى، جمل عسين

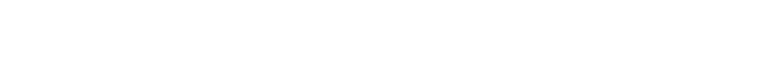
بمعارف ومماسست الريفيت المتعلقة بالحصول على الغذاء

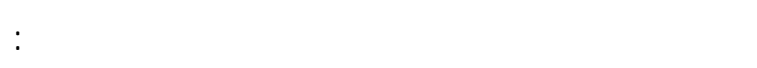

$$
01 \mu \text { - ع90 }
$$

Altekruse ‘S.F ‘D.A ‘.Street ، S.B ‘. Fein and A.S ،. Levy. 1996. Consumer Knowledge of foodborne microbial hazard and food-handing practices .J.Food. Prot. 59: 287249.

Borneff, J.R ‘. J., Hassinger, Witing,and R. Edenharder.1998. Effective hygienic measurements in households today. Zentra1b1.Bacteriol.Microbiol.Hyg., 187: 404-413.

Byrd- Bredbenner, C ،.J.Maurer ‘.Schaffner.D ‘.Wheatly.V ‘. ‘.Blalock.and L ‘.Bruhn.C2007.reported -Food safety self. Results of.behaviors and congnitions of young adults .Food Prot .national study j70: 1917-1926
ايملن للسيد الغول 1991، درلسة المعارف والممارست الصحية

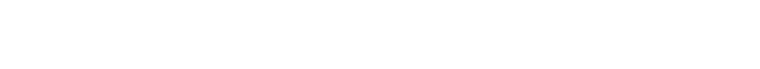

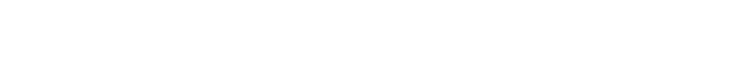

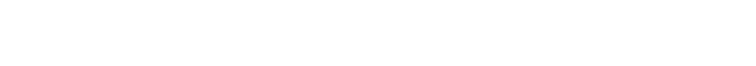
كلية الزراعة بجلمعة القاهرة. تسب محمود بشاد لطفى 1990، ققيم بررنلمج توعية غذائية للمرأة الريفية فى مجل تخطيط واعداد وتخزين الوجبلت

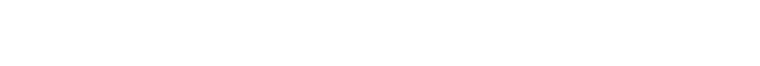
العدد الثالث والرالع.

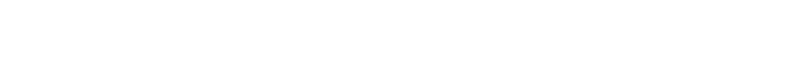

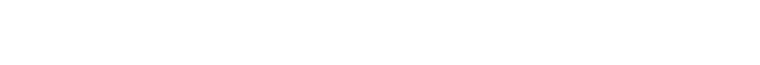

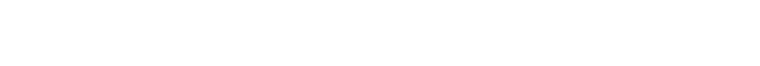
الاقتصاد المنزله، كلية الزراعة جلمعة الإسكندرية.

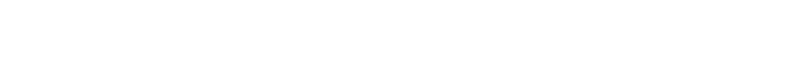

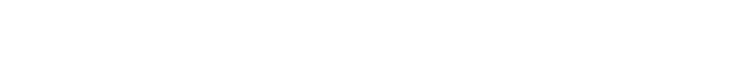

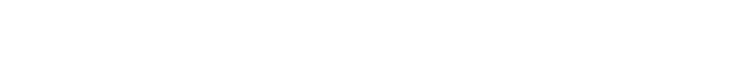

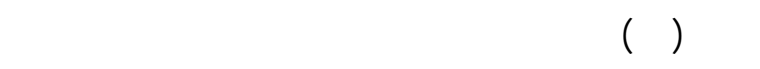
ص:- 0

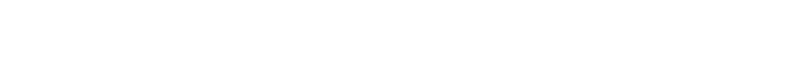
وسلامة الغذاء، درلسة لسقلاعية، المركز القومى للبحوث،

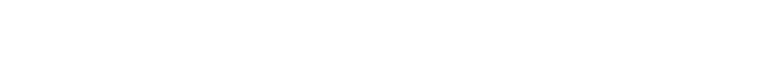

$$
\text { - مملكة البحرين. }
$$

سهير لويب توفق،، ليلى حماد الثناوى 199^، المستوى

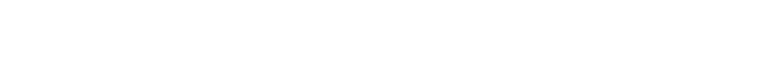

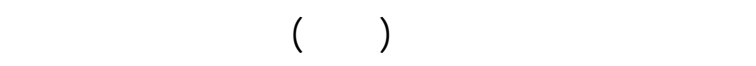
الزراعى والتنمية الريفية، مركز البحوث الزراعية.

شيرين ماهر ولكد، عزة عبد الكريم الجزار، فلطمة مصطف

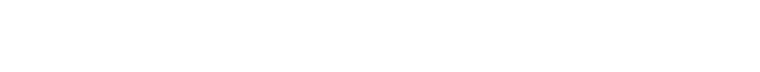
الصحيحة لإعداد وطه الغذاء فى بعض مض قرى محافظة

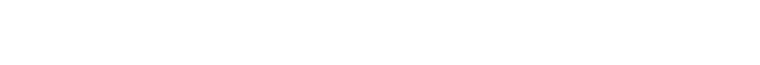

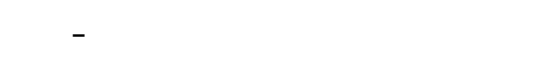


Mullan , B.A., and C.Wong. 2009 . Freezing Shelf In ". Hand book of frozen foods "، Y. H. Hui et et al (Ed). Marcel Dekker ، INC ‘. New York, pp .215 -220.

National Institute of Allergy and Infectious (N AID ). 2005. Foodborne Diseases . http : www.niaid.nih. gov/ factsheets /Foodboredis. Ntm

Patial ، SR ، .S. Cates a and R. Morales . 2005. Consumer food safety knowledge, Practice and demographic differences ? Findings from a meta- analysis. J.Food .Prot. 68:818-822

Redmond,E.C ‘. and C. J .Griffith .2003. Consumer food handing in the home: a review of food safety studies . J.Food .Prot .66: 130-161.

Trepka‘ M.J ‘.F.L.Newman ‘Z.Dixon .and F.G.Huffman.2008 . Food Safety Practices among pregnant women and mothers in the women' infants and children program, Miami ، Florida ‘.J.Food. Prot .70 (5) :1230-123

WHO 2002 .Food safety and foodborn illness . Fact sheets No237 . Media Centere http : www.who. int / media centre / Fact sheets / Fact sheet / Fs 237 /en.

Yang ، S.m ‘.F.J.Angulo ‘.and S.F Altekruse. 2000 . Evaluation of safe food -handing instructions on raw meat and poultry products .J.Food Prot . 63: 1321-1325.
(CDC)Centers for Disease Control 2004. Foodborne . Outbreak Response and Surveillaance Unit. 2003 Summary Statistics/ http www.cdc.gov./ foodbornoutbreaks \us outb/fbo2003/ Summary03.htm .

De Waal, C.S., 2003. Safe Food from a consumer perspective. Food Control. 42: 75-79..

Express Newspaper.2003.Bad food -handing practices in T\&T. In K.C.James Sr., Express Yourself by (via email).Monday $3^{\text {rd }}$ November. Port-of-Spain, Trinidad,West Indies,p.13.

FAO /WHO . 2003 . Codex Altmentarius, Basic Text on Food Hygiene. 3rd ed Italy.

FDA. Food and Drug Administration. 1999. Public Health Service. Food Code, Annex 5 HACCP Guidelines. Rockville, MD , U.S. Department oF Health and Human Services , ( C.F.www.cfsan .fda. gov/ mdms /Fs 99 -a5).

Getting, M. A r.and N.E .Kiernan. 2003. Future chalanges to microbial food safety. International Journal of Food Micrbiology. 30: 579-594.

Mitakakis, T.Z , M.I .Sinclair , CK .Fairly et al. 2004 Food safety in family homes in Melbourne, Australlia . J .Food .Prot. 67: 818-822

\title{
ABSTRACT \\ Rural Women Practices Related to Keeping Food Away from Contamination and Their Relation to Some Variables in Kafr Aldwar in Al Bohera Governorate.
}

\author{
Eman A.S.Ali, Hanan F. Z. Mekawy
}

This Research aimed to study some variables related to rural women's practices in keeping food away from contamination during the purchase,preparation, cooking, food handling and preservation after cooking ,regarding cleanliness and respondents beheviour in the kitchen .

Data were collected by questionnaire through personal interviews with random sample consisted of 140 rural respondents in Zohra and Aloken villages in Bohera Goveronrate.

Percentages, frequencies, person correlation and Chi square were used in data analysis.

\section{Data indicated the the following results:}

- $95.29 \%$ of respondents were found in the category of low level of keeping food away from contamination.
- $\quad 50.70 \%, 58.57 \%, 60.71 \%, 48.58 \%, 53.57 \%$ of respondents respectively were found in the category of middle level of keeping food away from contamination during purchase, preparation, cook, food preservation ,regarding cleanliness, respondents beheviour in the kitchen and total practices of keeping food away from contamination.

* A significant relationship was found between educational status of the respondents and their husbands as independent variables and keeping food away from contamination as dependent variables.

* Negative relationship was found between respondents age and family members as independent variables and keeping food away from contamination as dependent variables. 